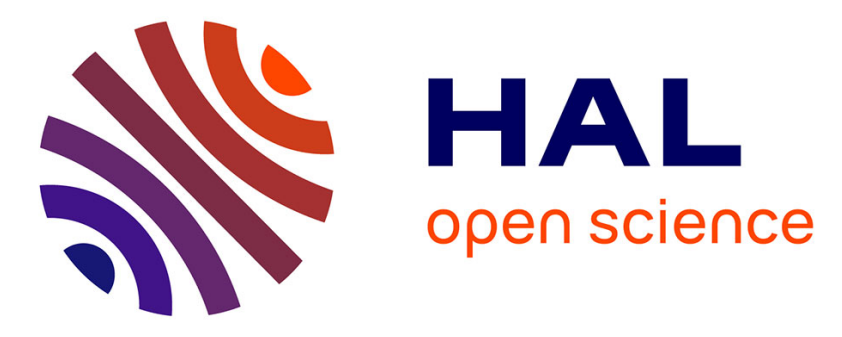

\title{
A 1.8-V 3.6-mW 2.4-GHz Fully Integrated CMOS Frequency Synthesizer for the IEEE 802.15.4
}

\author{
Manthena Vamshi Krishna, Xuan Jie, Anh Manh Do, Chirn Chye Boon, Kiat
}

Seng Yeo, Aaron Do

\section{- To cite this version:}

Manthena Vamshi Krishna, Xuan Jie, Anh Manh Do, Chirn Chye Boon, Kiat Seng Yeo, et al.. A 1.8-V 3.6-mW 2.4-GHz Fully Integrated CMOS Frequency Synthesizer for the IEEE 802.15.4. 18th International Conference on Very Large Scale Integration (VLSISOC), Sep 2010, Madrid, Spain. pp.6999, 10.1007/978-3-642-28566-0_4. hal-01516000

\section{HAL Id: hal-01516000 https://hal.inria.fr/hal-01516000}

Submitted on 28 Apr 2017

HAL is a multi-disciplinary open access archive for the deposit and dissemination of scientific research documents, whether they are published or not. The documents may come from teaching and research institutions in France or abroad, or from public or private research centers.
L'archive ouverte pluridisciplinaire HAL, est destinée au dépôt et à la diffusion de documents scientifiques de niveau recherche, publiés ou non, émanant des établissements d'enseignement et de recherche français ou étrangers, des laboratoires publics ou privés.

\section{(c)(1)}

Distributed under a Creative Commons Attribution| 4.0 International License 


\title{
A 1.8-V 3.6-mW 2.4-GHz fully integrated CMOS Frequency Synthesizer for the IEEE 802.15.4
}

\author{
M.Vamshi Krishna ${ }^{1}$, Xuan Jie ${ }^{1}$, Anh Manh Do ${ }^{1}$, Chirn Chye Boon ${ }^{1}$, Kiat Seng \\ $\mathrm{Yeo}^{1}$, Aaron V. T. Do ${ }^{2}$ \\ ${ }^{1}$ Nanyang Technological University, Singapore 639798 \\ \{mkvamshi, xiej0005, emado, eccboon, eksyeo\}@ntu.edu.sg \\ ${ }^{2}$ Marvell Asia Pte. Ltd., Singapore 534158 \\ \{doaaron\}@marvell.com
}

\begin{abstract}
This paper presents a low power 2.4-GHz fully integrated $1 \mathrm{MHz}$ resolution IEEE 802.15.4 frequency synthesizer designed using 0.18um CMOS technology. An integer-N fully programmable divider employs a novel Truesingle-phase-clock (TSPC) $47 / 48$ prescaler and a 6 bit P and S counters to provide the $1 \mathrm{MHz}$ output with nearly $45 \%$ duty cycle. The PLL uses a series quadrature voltage controlled oscillator (S-QVCO) to generate quadrature signals. The PLL consumes $3.6 \mathrm{~mW}$ of power at $1.8 \mathrm{~V}$ supply with the fully programmable divider consuming only $600 \mathrm{uW}$. The S-QVCO consumes 2.8 $\mathrm{mW}$ of power with a phase noise of $-122 \mathrm{dBc} / \mathrm{Hz}$ at $1 \mathrm{MHz}$ offset.
\end{abstract}

Keywords: D flip-flop (DFF), Frequency synthesizer, Phase-locked loop (PLL), Voltage controlled oscillator (VCO), Dual-modulus prescaler.

\section{Introduction}

Most of the wireless communication standards prior to IEEE 802.15.4/Zigbee were tailored towards high data rate and multimedia friendly applications. The need for low data rate and low power wireless solutions with emphasis on sensor network applications resulted in the development of IEEE 802.15.4 standard. The recent development and advanced scaling CMOS technologies have made it more attractive to implement a single chip CMOS wireless transceiver featuring both high level of integration and low power consumption [1].

The higher power consumption in the frequency synthesizer is mainly due to the VCO and the first stage divider which is driven by the VCO. The $2.4 \mathrm{GHz}$ synthesizer reported in [2] with a frequency resolution of $5 \mathrm{MHz}$ consumes a power of $7.85 \mathrm{~mW}$ at $1.8 \mathrm{~V}$ power supply in $0.18 \mathrm{um}$ CMOS technology. Here, the first stage divider is designed using current-mode logic (CML) [6] which consumes a large amount of power. The synthesizer reported in [3] consumes $2.4 \mathrm{~mW}$ at $1.2 \mathrm{~V}$ supply in $0.13 \mathrm{um}$ CMOS technology. It uses a 16/17 dynamic logic prescaler as first stage divider which consumes only $176 \mathrm{uA}$ at $2.5 \mathrm{GHz}$ and the complete divider is designed with 5 
$\mathrm{MHz}$ resolution. Here, the VCO provides only differential phase signals. The frequency synthesizer reported in [4] proposes a new spur suppression technique, but consumes a power of $18 \mathrm{~mW}$. Reference [5] provides a synthesizer for IEEE 802.15.4/Zigbee applications consumes a power of $15 \mathrm{~mW}$ in 0.18 um CMOS technology. For the popular transceiver's architecture shown in Fig.1 with direct upconversion for the TX and low IF down-conversion, the synthesizer needs to generate LO outputs having both I-Q outputs. In this article, an integer-N, low power $2.4 \mathrm{GHz}$ frequency synthesizer with quadrature signal generation is proposed. In this design, the fully programmable $1 \mathrm{MHz}$ resolution divider is implemented using dynamic logic circuits.

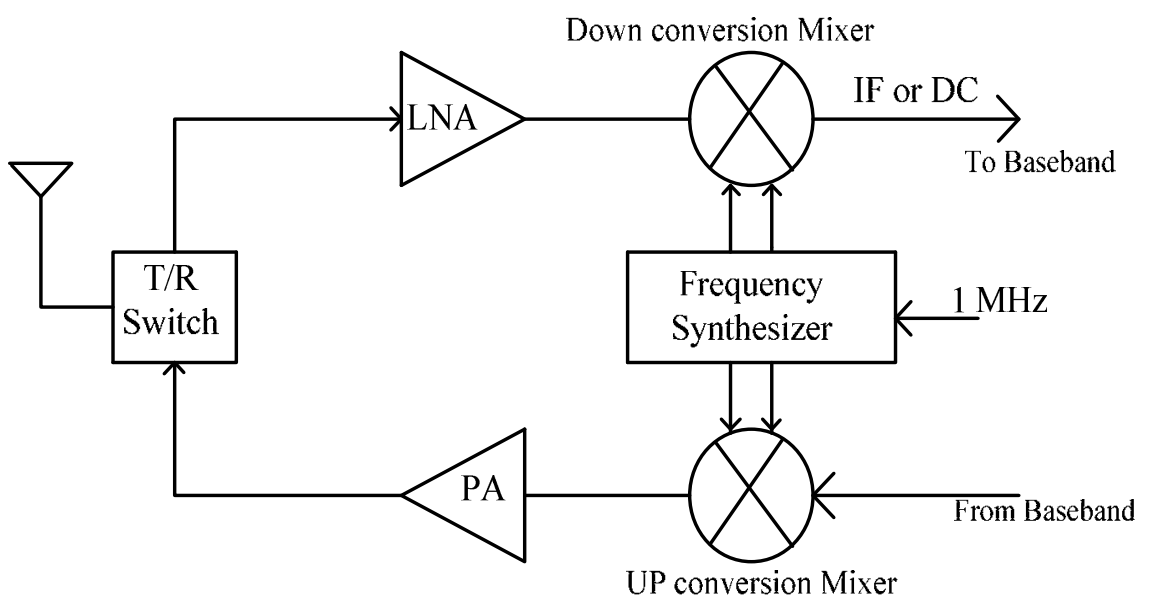

Fig. 1. Transceiver architecture.

\section{System Specification}

\subsection{Frequency Synthesis}

The IEEE 802.15.4 standard has 16 channels, spaced at $5 \mathrm{MHz}$ apart over the frequency range from $2405 \mathrm{MHz}$ to $2480 \mathrm{MHz}$. The synthesizer needs to synthesize 16 channel selection frequencies with 40-ppm frequency accuracy. If direct conversion is used in both the transmitter and receiver, then the 16 channel selection frequencies would be from $2405 \mathrm{MHz}$ to $2480 \mathrm{MHz}$ in steps of $5 \mathrm{MHz}$. If a low IF architecture is used for the RX, then the local oscillator frequencies could be different from the channel frequencies for both the transmitter and receiver. In order to have more flexibility to accommodate channel selections for both kind of architecture, the resolution of the divider and reference frequency chosen is $1 \mathrm{MHz}$ which gives a 
resolution of $1 \mathrm{MHz}$ to the channel selection frequency. For example, if the IF frequency is chosen to be $2 \mathrm{MHz}$, the divider is programmed to have the local oscillator frequencies equal to $2403,2408 \ldots .2478 \mathrm{MHz}$ or $2407,2412 \ldots .2482 \mathrm{MHz}$. For the IEEE 802.15.4 standard, the channel bandwidth is $2 \mathrm{MHz}$.

\subsection{Phase Noise}

According to [7], the required phase noise at a frequency offset determined by the frequency offset of $P_{\text {int }}$ can be calculated by,

$$
P N(d B c / H z)=\left(P_{s i g}-P_{i n t}\right)-S N R_{r e q}-10 \log (B W)
$$

The system simulations in [8] shows that $S N R_{\text {out }}$ should be at least $14 \mathrm{~dB}$. Based on this value, from (1) the required phase noise at $5 \mathrm{MHz}$ offset and $10 \mathrm{MHz}$ offset would be $-77 \mathrm{dBc} / \mathrm{Hz}$, and $-107 \mathrm{dBc} / \mathrm{Hz}$ respectively. Assuming a margin of $10 \mathrm{~dB}$ due to non-idealities of the system, the required phase noise at $5 \mathrm{MHz}$ offset and $10 \mathrm{MHz}$ offset is $-87 \mathrm{dBc} / \mathrm{Hz}$ and $-117 \mathrm{dBc} / \mathrm{Hz}$ respectively.

\subsection{Spur Rejection}

The IEEE 802.15.4 standard specifies the adjacent channel interference of $+0 \mathrm{~dB}$ (relative to the carrier) at an offset of $5 \mathrm{MHz}$. The spur suppression requirement for the synthesizer can be calculated by [5]

$$
P N(d B c / H z)=\left(P_{s i g}-P_{i n t}\right)-S N R_{r e q}-10 \log (B W)
$$

For the IEEE 802.15.4 standard, the required spur suppression is $-14 \mathrm{dBc}$ at $5 \mathrm{MHz}$ offset, and $-44 \mathrm{dBc}$ at $10 \mathrm{MHz}$ offset.

\subsection{Settling time}

The IEEE 802.15.4 supports a data rate of $250 \mathrm{Kbps}$ with each symbol consisting of 4-bits and a symbol rate of $62.5 \mathrm{Ksymbols} / \mathrm{sec}$. The maximum Tx-Rx turn-around time is 12 symbol periods, which is equivalent to 192 us. Thus the worst case settling time of the synthesizer is estimated to be 192 us.

The synthesizer is designed to meet all the above specifications with a supply voltage of $1.8 \mathrm{~V}$ and low power consumption with on-chip filter in RF CMOS 01.8um technology. 


\section{Architecture of the implemented frequency synthesizer}

The synthesizer is designed to generate quadrature differential output signals of 1 $\mathrm{MHz}$ resolution over the $2.4 \mathrm{GHz}$ ISM band. The architecture of the frequency synthesizer is chosen to be a type-2, fourth order loop using a charge pump as shown in Fig.2. The synthesizer consists of a phase-frequency detector (PFD), a charge pump (CP), a series Q-VCO, a $3^{\text {rd }}$ order loop filter and a fully programmable $1 \mathrm{MHz}$ resolution divider.

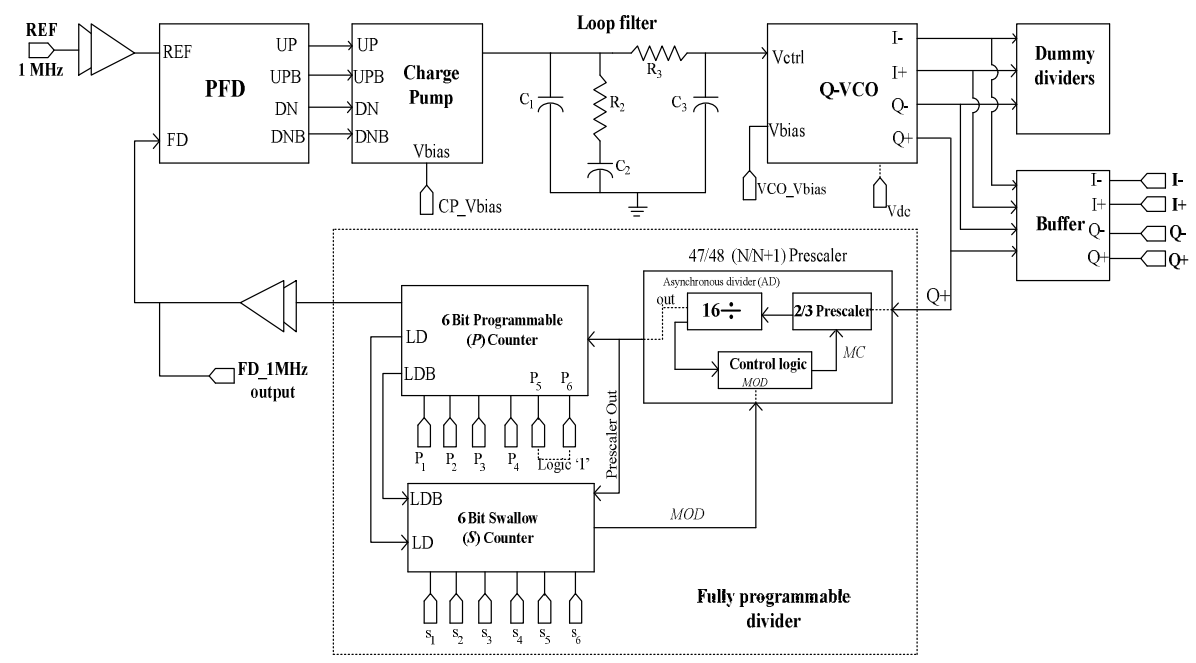

Fig. 2. System Level architecture of the implemented $2.4 \mathrm{GHz}$ frequency synthesizer

Compared to lower order loop, the additional poles provide higher spurious filtering, thus reducing the spurs generated by the input reference without decreasing the loop bandwidth or increasing the settling time. Since the divider is based on dynamic logic circuits whose input is single-phase, only one of the outputs of the quad-phase VCO is applied to the divider while the remaining 3 outputs of the VCO are connected to the dummy divider loads. Based on the optimization of the loop parameters, the loop bandwidth is chosen to at $45 \mathrm{KHz}$ as described in section 6 .

\section{Fully Programmable 1 MHz Resolution Divider}

The fully programmable $1 \mathrm{MHz}$ resolution divider used in this design is based on the pulse-swallow topology shown in Fig.3. The pulse-swallow frequency divider consists of a dual-modulus prescaler (DMP), a programmable (P) counter and a swallow (S) counter. The dual-modulus prescaler is based on both synchronous and asynchronous divider which scales the input frequency to a lower frequency to ease the complexity of asynchronous presettable modulo-P and modulo-S counters. In this 
technique, $\mathrm{S}$ input pulses are swallowed in the preceding arrangement such that the output period becomes longer by $\mathrm{S}$ reference periods.

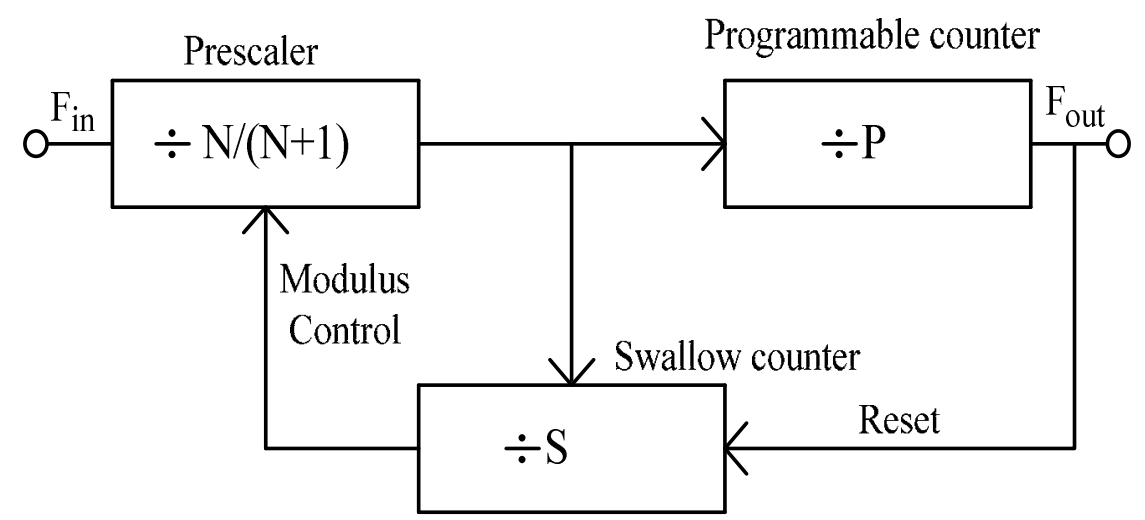

Fig. 3. Pulse-swallow frequency divider

In the initial state, the modulus control (MC) signal remains at logic ' 0 ' and allows the DMP to operate in the divide-by- $(\mathrm{N}+1)$ mode and the programmable P-counter and swallow $\mathrm{S}$ counter are loaded to their initial states. Since P>S, the S-counter reaches the final state earlier than P-counter and the end-of-count logic of the Scounter changes the $M C$ to logic ' 1 ' allowing the DMP to switch to divide-by-N mode where the P-counter counts the remaining (P-S) input periods of ' $\mathrm{N}$ '. Thus the total division ratio is given by

$$
\mathrm{F}_{\text {out }}=((\mathrm{N}+1) \mathrm{S}+\mathrm{N}(\mathrm{P}-\mathrm{S})) \mathrm{F}_{\mathrm{in}}=(\mathrm{NP}+\mathrm{S}) \mathrm{F}_{\text {in }}
$$

In this design, the fully programmable divider is constructed using a TSPC [9] $47 / 48(\mathrm{~N} / \mathrm{N}+1)$ dual-modulus prescaler, a 6-bit programmable $\mathrm{P}$-counter and a 6-bit swallow S-counter.

\subsection{A TSPC 47/48 Dual-modulus prescaler}

The proposed 47/48 prescaler circuit as shown in Fig.4 is similar to the 32/33 prescaler reported in [10] except for an additional inverter which is added between the output of the NAND2 gate and the control signal $(M C)$ input of the $2 / 3$ prescaler. The $47 / 48$ prescaler consists of $2 / 3$ prescaler [10], four asynchronous divide-by-2 circuits and additional logic gates to control the division ratio between 47 and 48 . When $M C={ }^{\prime} 0$ ', the $2 / 3$ prescaler of the $32 / 33$ prescaler in [10] operates in divide-by-3 mode whereas the $2 / 3$ prescaler in the proposed $47 / 48$ prescaler operates in divide-by- 2 mode. Thus the inverter swaps the operation modes of the $2 / 3$ prescaler. 


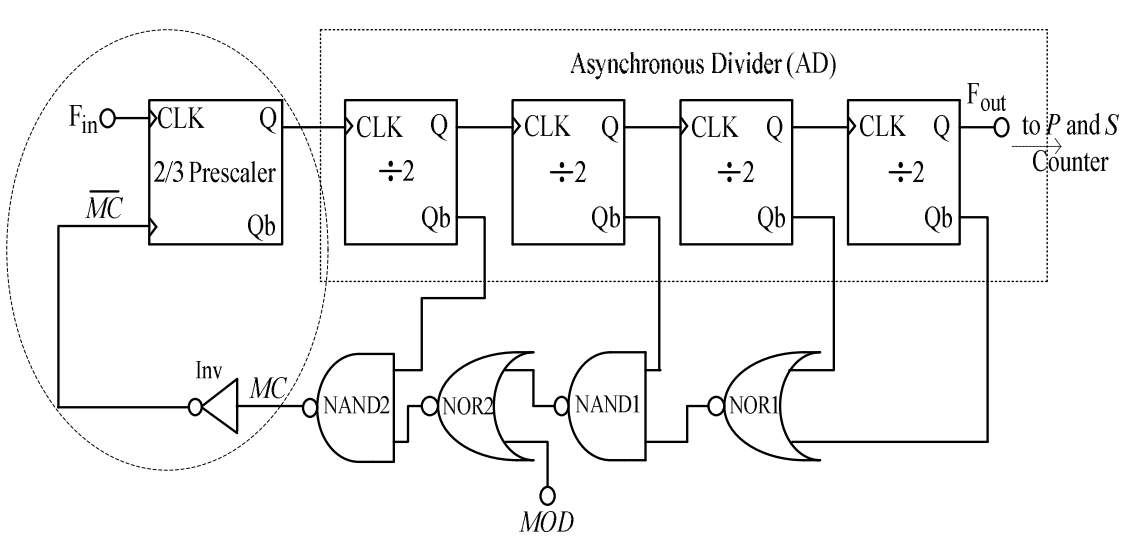

Fig. 4. Proposed TSPC $47 / 48$ prescaler

Divide-by-48 operation (MOD='1'): When the control signal $M O D$ is ' 1 ', the output of NOR2 in Fig.4 always remains at logic ' 0 ' and forces the output of NAND2 to logic ' 1 ' irrespective of data on $\mathrm{Q}_{\mathrm{b} 1}$. Since $M C$ is always equal to logic ' 1 ' ( $\overline{M C}={ }^{\prime} 0$ '), the $2 / 3$ prescaler remains in divide-by- 3 mode. The equivalent circuit of inverter and the $2 / 3$ prescaler is equal to divide-by-3 counter as shown in Fig.5. Thus the 47/48 prescaler operates in divide-by-48 mode when $M O D=$ '1'. Fig.6 shows the transient simulations of divide-by-48 mode of operation. If we denote the synchronous $2 / 3$ prescaler as $M / M+1$ and the four asynchronous dividers whose division ratio equal to 16 by 'AD', the division ratio of the $47 / 48$ prescaler in this mode $(M O D=' 1$ ') is given by

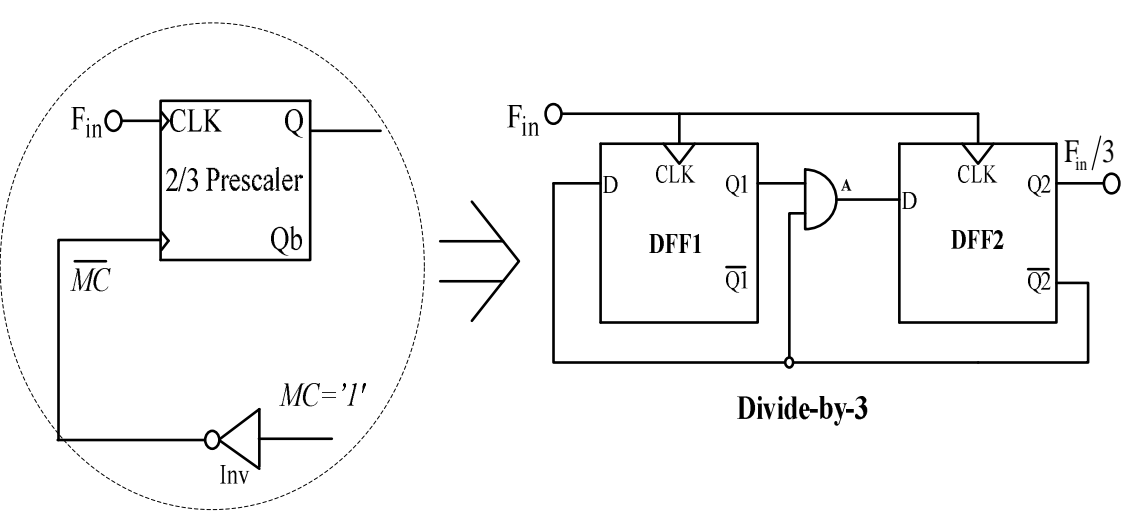

Fig. 5. Divide-by-48 mode of operation

$\mathrm{F}_{48}=(\mathrm{AD}-\overline{M O D}) \times(\mathrm{M}+1)+\overline{M O D} \times \mathrm{M}=(16-0) \times(2+1)+0 \times 2=48$ 


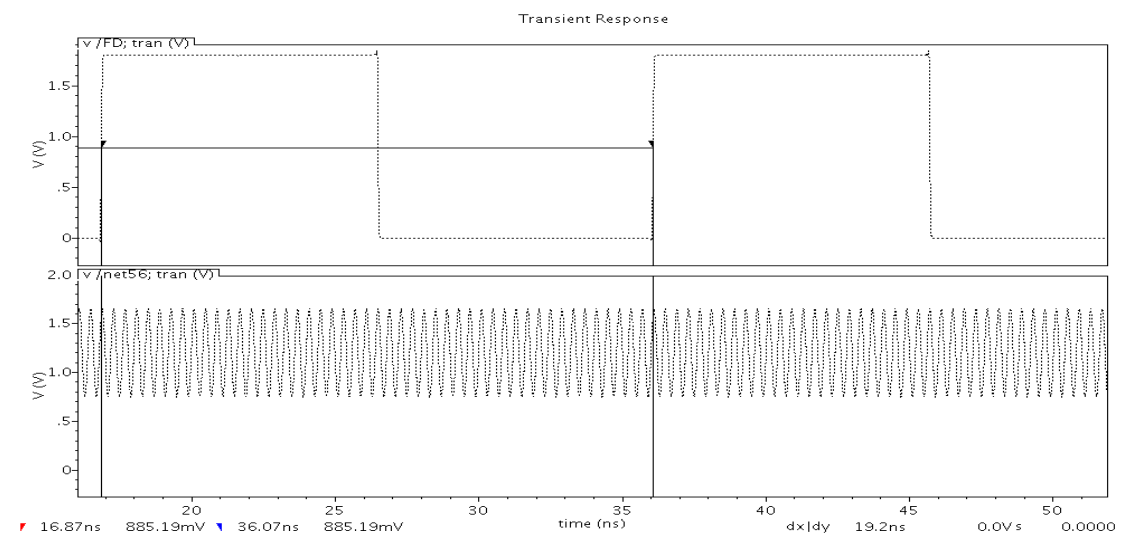

Fig. 6. Transient simulations of divide-by- 48 mode of operation

Divide-by-47 operation (MOD='0'): The proposed 47/48 prescaler operates as divide-by-47 when $M O D=' 0$ '. By using the combination of logic NOR and NAND gates, the asynchronous divide-by-16 counter is made to count an extra input clock. In the initial state, the $2 / 3$ prescaler will be in divide-by-3 mode ( $M C=$ ' 1 ') and the asynchronous divide-by16 starts counting the output pulses of $2 / 3$ prescaler from "0000" to "1111". When the asynchronous counter value reaches " 1110 ", the logic signal MC goes low (MC='0') and 2/3 prescaler operates in divide-by-2 mode, where the asynchronous counter counts an extra input clock pulse. During this operation, the $2 / 3$ prescaler operates in the divide-by- 3 mode for 45 input clock cycles and in the divide- 2 mode for 2 input clock cycles. The division ratio of the $47 / 48$ prescaler in this mode is given by

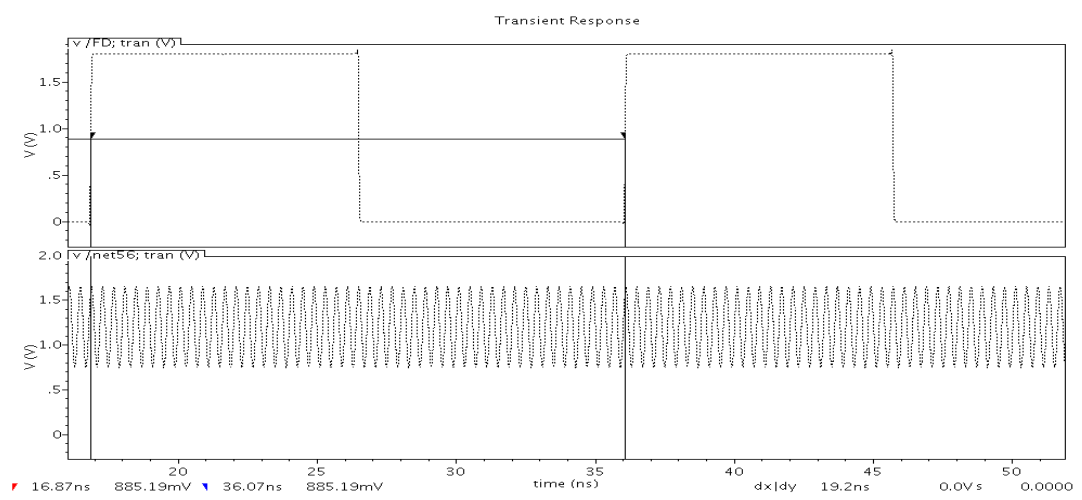

Fig. 7. Transient simulations of divide-by-47 mode of operation

The transient simulation of divide-by-47 mode of operation is shown in Fig.7. The Post layout simulation results shows that the proposed dual modulus $47 / 48$ prescaler 
consumes a current of $269.3 \mathrm{uA}$ and $262.8 \mathrm{uA}$ during the divide-by-47 and divide-by48 modes respectively and the maximum operating frequency is $4.8 \mathrm{GHz}$.

\subsection{A Low Power TSPC 2/3 Prescaler [10]}

Fig. 8 shows the ultra-low power TSPC $2 / 3$ prescaler reported in [10]. In this design, an extra PMOS transistor $\mathrm{M}_{1 \mathrm{a}}$ is connected between the power supply and DFF1 whose input is the controlled by the logic signal $M C$. As discussed in the section 3.6.1, during the divide-by-2 operation, one of the input logic signals MC. During the divide-by-2 operation, one of the inputs of second NOR gate is always zero since transistor $\mathrm{M}_{10}$ blocks the data at the input of DFF1 to propagate to the output node.

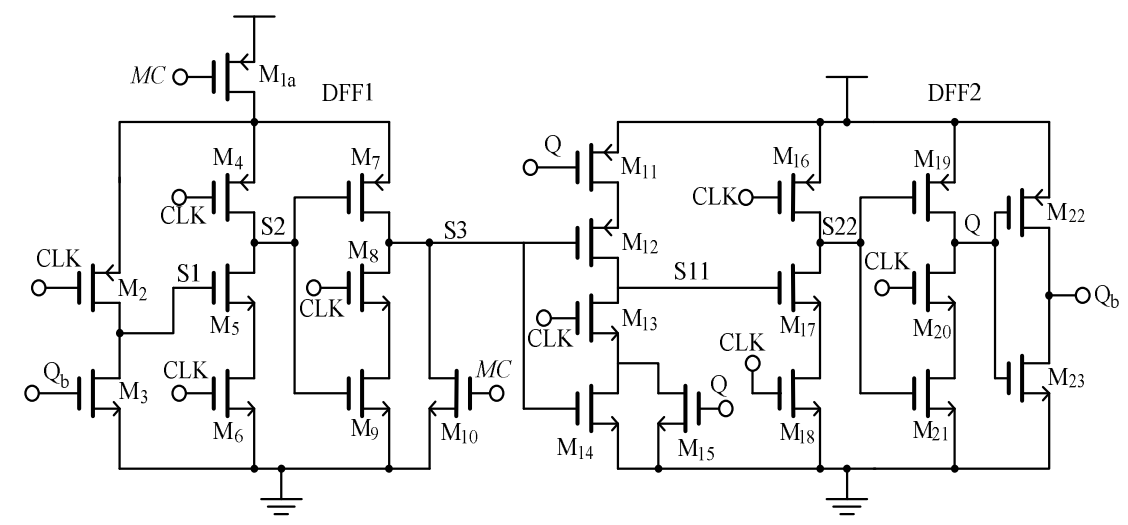

Fig. 8. Ultra-low power TSPC $2 / 3$ prescaler [10]

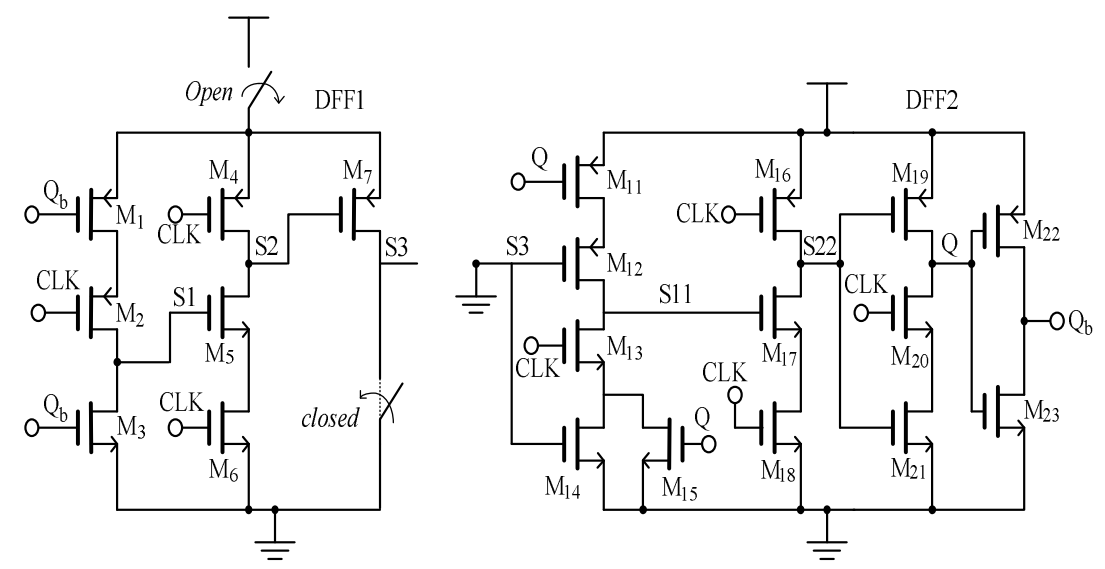

Fig. 9. Divide-by-2 operation of the ultra-low power TSPC $2 / 3$ prescaler [10] 
In this design, when the control logic signal $M C$ is ' 1 ' during the divide-by-2 mode, the PMOS transistor $\mathrm{M}_{1 \mathrm{a}}$ is turned-off and DFF1 is disconnected from the power supply. Fig. 9 shows the simplified schematic of the $2 / 3$ prescaler in the divideby-2 mode of operation. Even though $\mathrm{M}_{10}$ is always turned-on, the source of $\mathrm{M}_{7}$ is at virtual ground and short-circuit power is completely avoided. Even if the output ' $\mathrm{Q}_{\mathrm{b}}$ ' switches continuously, the nodes $\mathrm{S} 1$ and $\mathrm{S} 2$ and $\mathrm{S} 3$ always remain at logic ' 0 ' and thus the switching activities are blocked in DFF1 resulting in zero switching power.

The ultra-low power $2 / 3$ prescaler is fabricated using the chartered 1 P6M $0.18 \mathrm{um}$ CMOS process and the PMOS and NMOS transistor sizes are fixed to $3 \mathrm{um} / 0.18 \mathrm{um}$, 2 um/0.18 um respectively. On-wafer measurements are carried out using an 8 inch RF probe station. The input signal for the measurement is provided by the $83650 \mathrm{~B} 10$ MHZ-50 GHz HP signal generator and the output signals are captured by the Lecroy Wave master 8600A 6G oscilloscope.

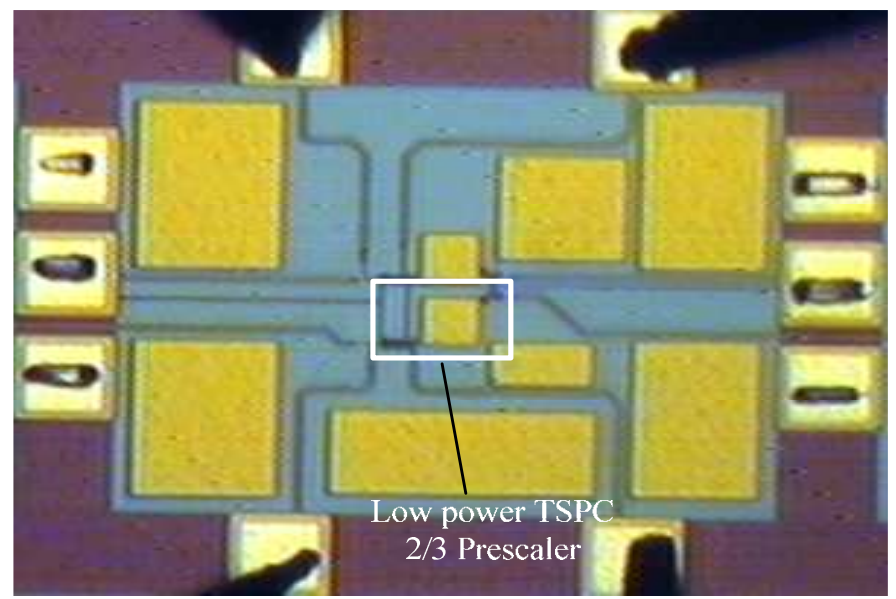

Fig. 10. Die photograph of the ultra-low power TSPC $2 / 3$ prescaler

Fig.10 shows the die photograph of ultra-low power TSPC 2/3 prescaler fabricated in Global foundries 0.18um CMOS technology. The measured maximum operating frequency of $2 / 3$ prescaler is $4.9 \mathrm{GHz}$. The power consumption of the $2 / 3$ prescaler during the divide-by- 2 and divide-by- 3 modes is $0.6 \mathrm{~mW}, 0.922 \mathrm{~mW}$ respectively, when the input frequency is $4.8 \mathrm{GHz}$. Fig. 11 shows the measured output waveforms of the $2 / 3$ prescaler at $4.8 \mathrm{GHz}$ during the divide-by- 2 and divide-by- 3 modes of operation. 


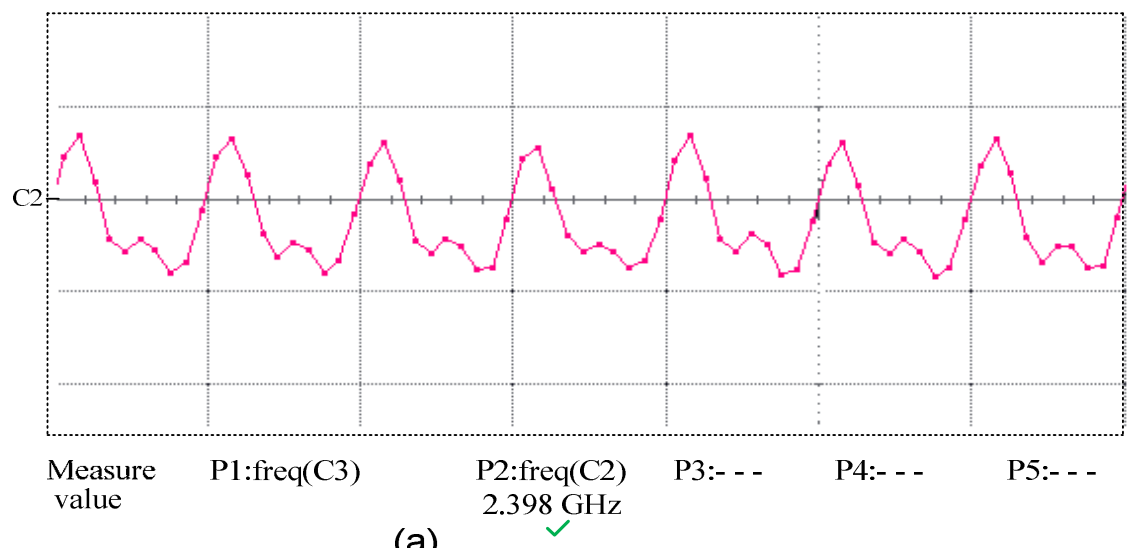

(a)

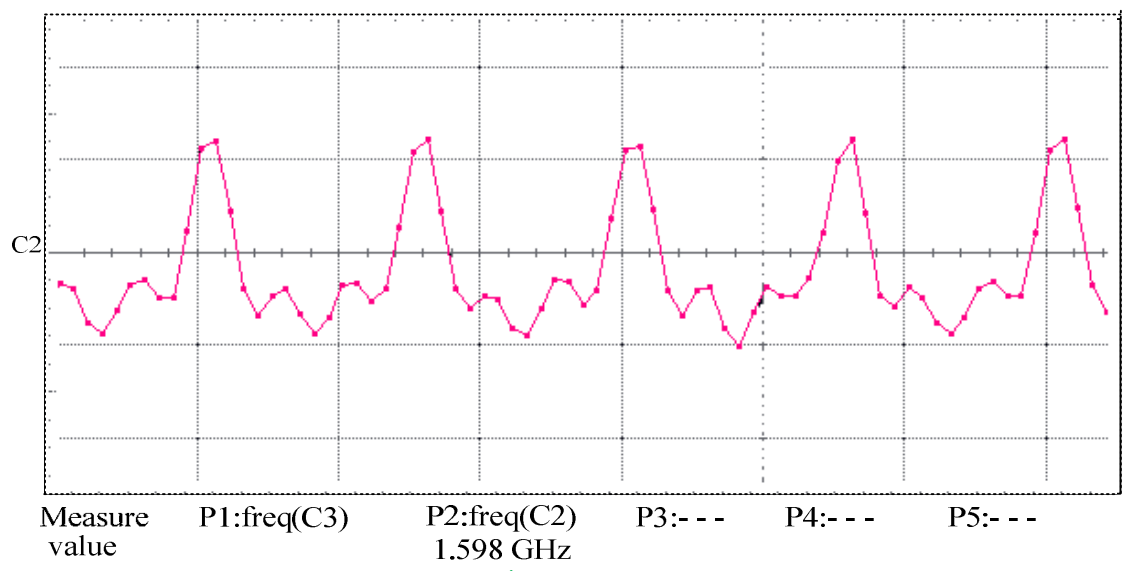

(b)

Fig. 11. Measured waveforms of the proposed prescaler at $4.8 \mathrm{GHz}$ (a) divide-by-2 mode, (b) divide-by-3 mode

\subsection{Programmable P-counter}

The 6 bit programmable P-counter used in the design of fully programmable divider is shown in Fig. 12. It consists of proposed 6 asynchronous reloadable bit-cells [11], a NOR-embedded DFF [12] and an end-of-count (EOC) detector with reload circuit. Here, bit $\mathrm{P}_{6}$ and $\mathrm{P}_{5}$ are always at logic '1' and bit $\mathrm{P}_{4}$ at logic '0' to have a programmable values of 51 and 52. By choosing a fixed value of 51 and 52, the swallow $\mathrm{S}$-counter is programmed in steps of one-bit to provide a division ratio from 2400 to 2484 with $1 \mathrm{MHz}$ resolution. 


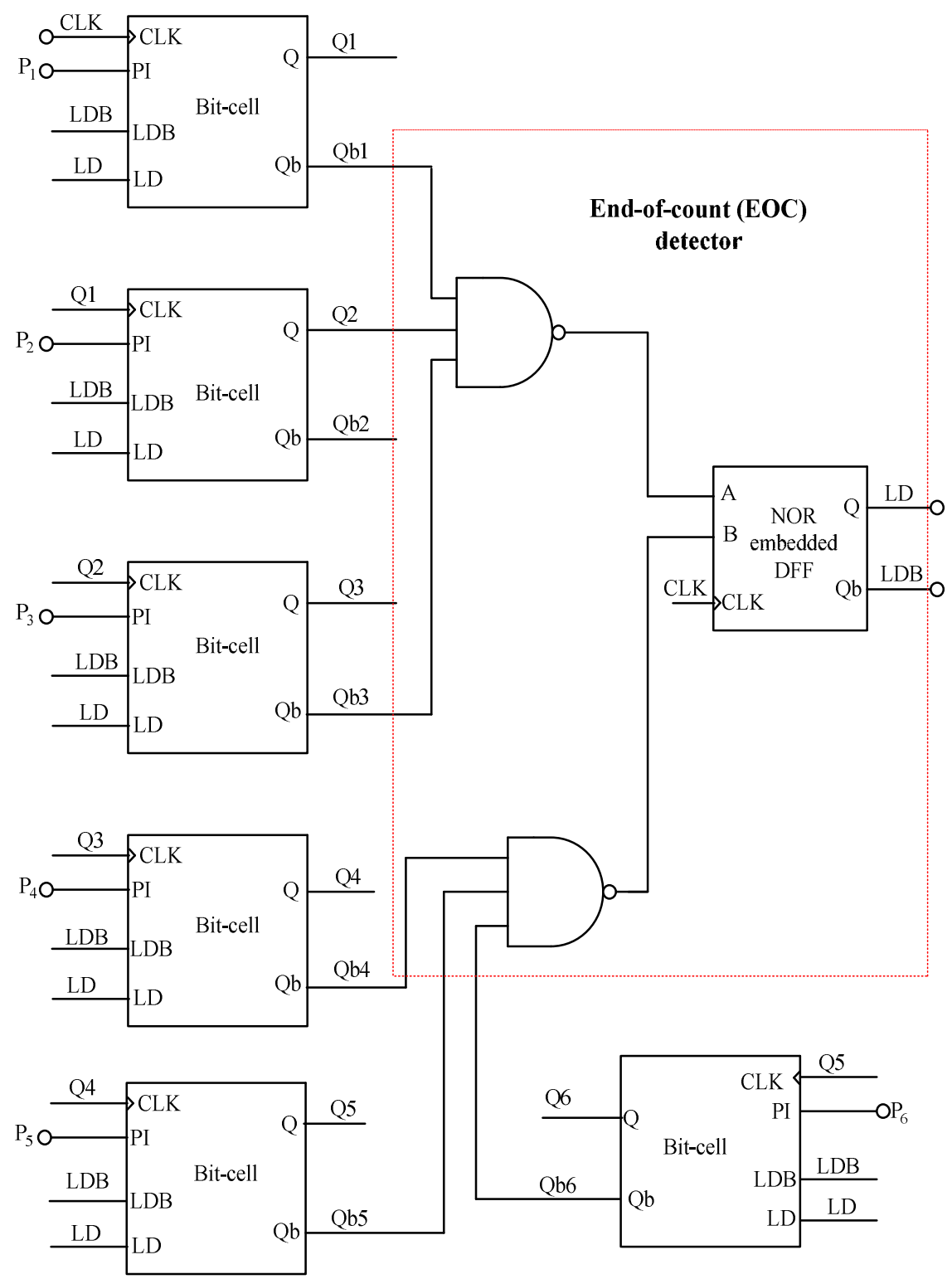

Fig. 12. A 6-bit Programmable P-counter with EOC logic circuit

In this design, the state $\mathrm{Q}_{6} \mathrm{Q}_{5} \mathrm{Q}_{4} \mathrm{Q}_{3} \mathrm{Q}_{2} \mathrm{Q}_{1}=$ ="000010" is detected by the EOC logic circuit. As soon as the state " 0000010 " is reached, the signals A and B go low after a delay introduced by the logic gates which is assumed to be less than half of the input clock cycle. However, the output of the embedded-NOR gate is latched to output only at the next rising edge of clock after the state "0000001" is reached. This output "LD" signal will initialize the $\mathrm{P}$ and $\mathrm{S}$ counters and the counting process continues. If the 
state "0000001" is chosen to detect, then it results in the undercounting due to the delays.
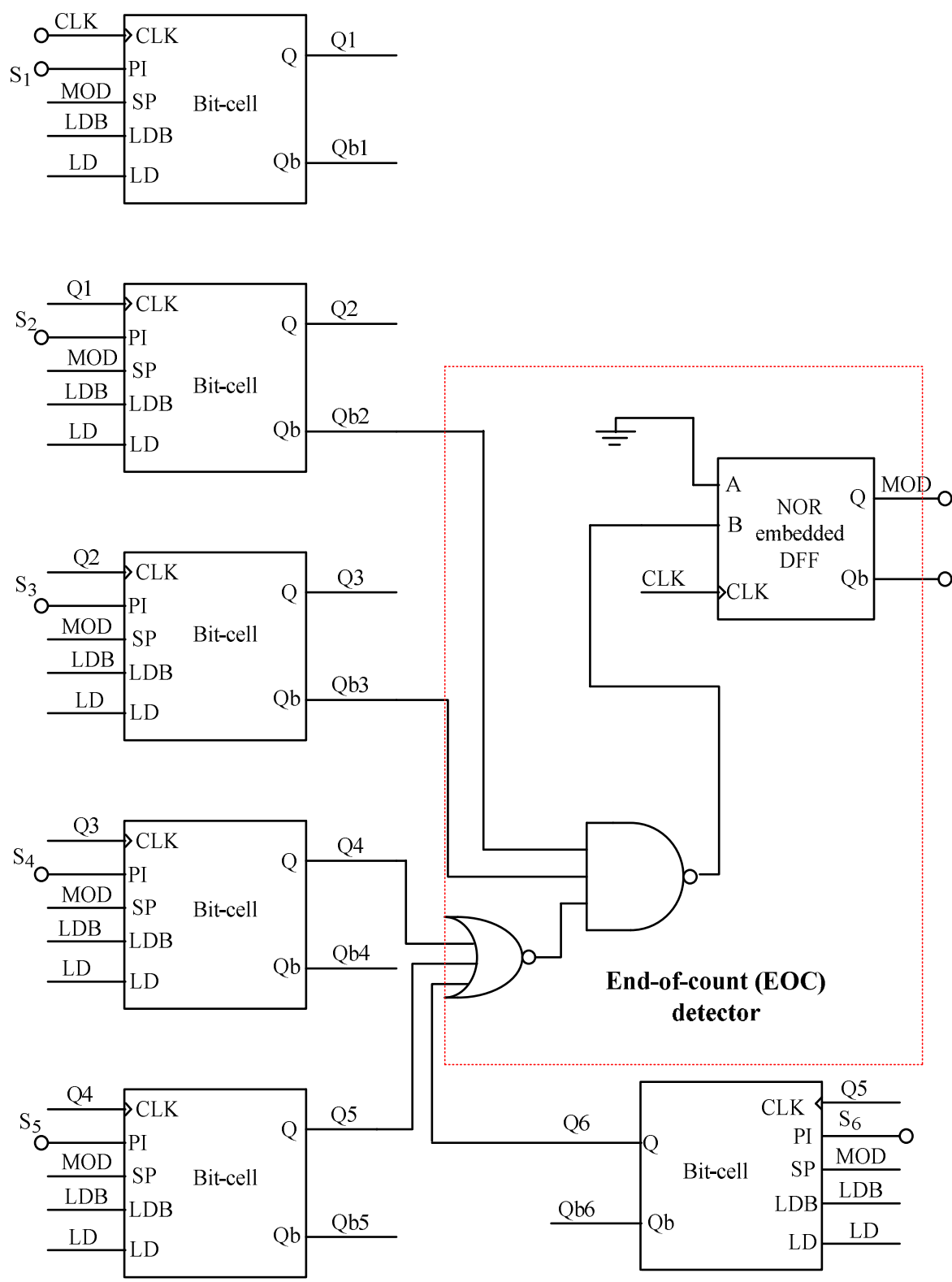

Fig. 13. A 6-bit Swallow S-counter with EOC logic circuit 


\subsection{Swallow S-counter}

The 6 bit swallow S-counter used in the fully programmable divider is shown in Fig. 13. It consists of proposed 6 asynchronous reloadable bit-cells, a NOR-embedded DFF [12] and an end-of-count (EOC) detector with reload circuit. Here the state $\mathrm{Q}_{6} \mathrm{Q}_{5} \mathrm{Q}_{4} \mathrm{Q}_{3} \mathrm{Q}_{2}=$ " 000000 " is detected by the EOC logic circuit. The S-counter in this programmable divider can be programmed from 0-47 in steps of 1 for a fixed value of the P-counter.

Since the counter is asynchronous and based on the ring topology, the complementary output of the first DFF is fed as the clock signal to the input of next flip-flop. In the initial state, all the reloadable FF's are loaded by the programmable value set by pins $S_{1}-S_{6}$. In the S-counter all states from 0-47 are usable and adjustable in steps of 1 to obtain a resolution of $1 \mathrm{MHz}$. Once the counter is triggered by the output of the prescaler, the S-counter starts down counting till the final state is reached, which is detected by the EOC logic circuit and the MOD signal goes high until the P-counter finishes its counting. Since the value of ' $\mathrm{P}$ ' is always greater than value of ' $\mathrm{S}$ ' in pulse-swallow divider, the $\mathrm{S}$-counter remains idle for a period of $(\mathrm{P}$ $\mathrm{S}) * \mathrm{~N}$ clock cycles.

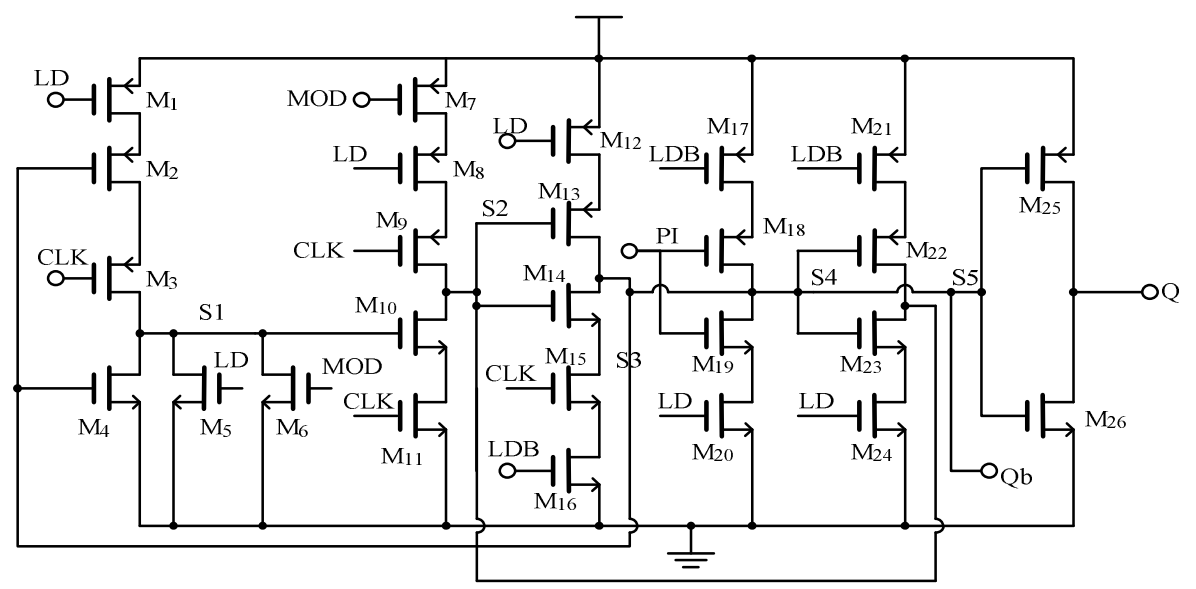

Fig. 14. Reloadable TSPC DFF for S-counter

The signal MOD goes high only when the outputs of all the reloadable DFF in the $\mathrm{S}$-counter go low and remain in the same state until the LD signal from the P-counter goes high. The state where MOD remains at logic high indicate the S-counter has finished counting. The S-counter cannot use the EOC logic circuit of the P-counter since MOD has to remain high until the P-counter reaches the state " 0000010 " when the LD signal goes high for one clock cycle. Moreover in the S-counter, all zero state is detected by EOC circuit unlike in the P-counter.

Fig.14 shows the schematic of an improved reloadable TSPC DFF used in the design of 6-bit S-counter. This reload DFF is similar to the reloadable DFF used in the design of P-counter [11]. However, the reloadable DFF for the S-counter needs an extra logic function MOD to be incorporated. When MOD goes high, the S-counter 
remains idle for a period of $\mathrm{N} *(\mathrm{P}-\mathrm{S})$ clock cycles and the reloadable DFF of the $\mathrm{S}$ counter consumes some switching power. In the improved design, transistors $\mathbf{M}_{6}$ and $\mathrm{M}_{7}$ are added to reduce the switching activities in the reloadable DFF. When the state "0000" is reached, MOD goes high, $\mathrm{M}_{6}$ is turned-on and $\mathrm{M}_{7}$ is turned-off such that node S1 and S2 remain at logic ' 0 ' for the remaining $\mathrm{N}^{*}(\mathrm{P}-\mathrm{S})$ clock cycles until LD becomes high. During this period, since $\mathrm{LD}={ }^{\prime} 0$ ', the right hand side portion of the circuit is de-activated similar to the reloadable DFF reported in [11]. Thus there is no switching activity at any node during the idle state of the S-counter and switching power is saved for a period of $\mathrm{N}^{*}(\mathrm{P}-\mathrm{S})$ clock cycles.

Table 1. Operation of the Reloadable DFF of the S-counter

\begin{tabular}{|c|c|c|c|}
\hline MOD & Load (LD) & Programmable Input (PI) & Output (Q) \\
\hline 1 & $X$ & $X$ & 1 \\
\hline 0 & 0 & 0 & CLK/2 \\
\hline 0 & 0 & 1 & CLK/2 \\
\hline 0 & 1 & 0 & 0 \\
\hline 0 & 1 & 1 & 1 \\
\hline
\end{tabular}

In other conditions, the operation of the improved reloadable DFF for S-counter is similar to the operation of the reloadable DFF used for the P-counter described in previous section. Table 1 shows the operation of reloadable DFF used in the $\mathrm{S}$ counter. In this design, the $\mathrm{P}$-counter is programmable from 51 to $52\left(\mathrm{P}_{1}\right.$ and $\mathrm{P}_{2}$ are only programmable) and the $S$-counter is programmable from 0 to $47\left(S_{1}\right.$ to $\left.S_{6}\right)$ in steps of 1 to accommodate division ratios from 2400 to 2484 . The frequency division (FD) performed by the programmable divider is given by,

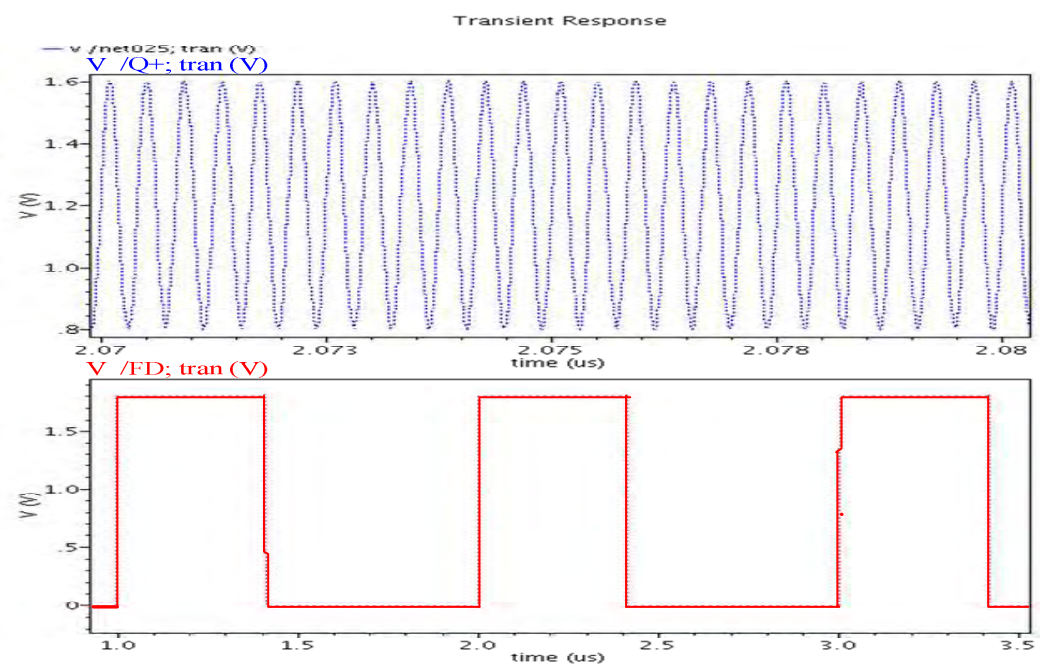

Fig. 15. Post layout results of the fully programmable divider with 2400 division ratio 


$$
F D=N \times S+((N+1) \times(P-S))=((N+1) \times P)-S
$$

The fully programmable divider at $2.4 \mathrm{GHz}$ consumes a power of $0.6 \mathrm{~mW}$. Fig. 15 shows the post layout results of the fully programmable divider at $2.4 \mathrm{GHz}$ with 1 $\mathrm{MHz}$ output signal of the divider having nearly $45 \%$ duty cycle. The $\mathrm{P}$ and $\mathrm{S}$ counter's programmable value for the division ratios between $2400-2484$ is shown in Table 2 .

Table 2. Programmable values of the programmable counters

\begin{tabular}{|c|c|c|c|}
\hline $\begin{array}{l}\text { Frequency } \\
\text { division ratio }\end{array}$ & $\begin{array}{l}\text { Prescaler } \\
(\mathbf{N} / \mathbf{N}+1)\end{array}$ & $\begin{array}{l}\text { Programmable-counter } \\
(\mathbf{P})\end{array}$ & $\begin{array}{l}\text { Swallow } \\
\text { counter (S) }\end{array}$ \\
\hline $2400-2448$ & $\mathrm{~N}=47$ & $\mathrm{P}=51$ & $\mathrm{~S}=0-47$ \\
\hline $2449-2484$ & $\mathrm{~N}=47$ & $\mathrm{P}=52$ & $\mathrm{~S}=14-47$ \\
\hline
\end{tabular}

\section{Quadrature Voltage-Controlled Oscillator (QVCO)}

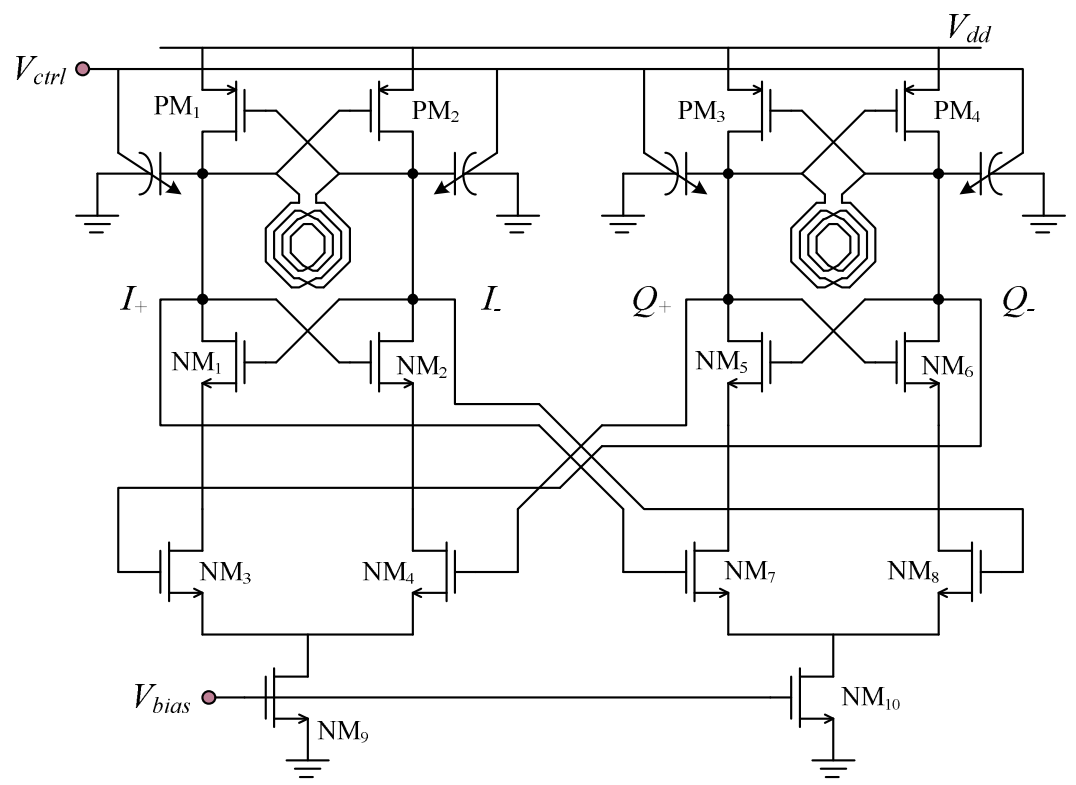

Fig. 16. Schematic of the implemented Q-VCO 
The VCO implemented in this design is a series quadrature VCO (S-QVCO) and its schematic is shown in Fig.16. The S-QVCO has been proven to eliminate the trade-off between phase noise and I/Q mismatch [13]. Therefore, the design can be optimized for phase noise performance, while keeping I/Q mismatch low. Compare to the parallel QVCO, the coupling transistors $\mathrm{NM}_{3}-\mathrm{NM}_{4}$ and $\mathrm{NM}_{7}-\mathrm{NM}_{8}$ are in series with the switching transistors $\mathrm{NM}_{1}-\mathrm{NM}_{2}$ and $\mathrm{NM}_{5}-\mathrm{NM}_{6}$. Hence the tail current for the coupling transistor is removed and the S-QVCO consumes less power.

Transient Response

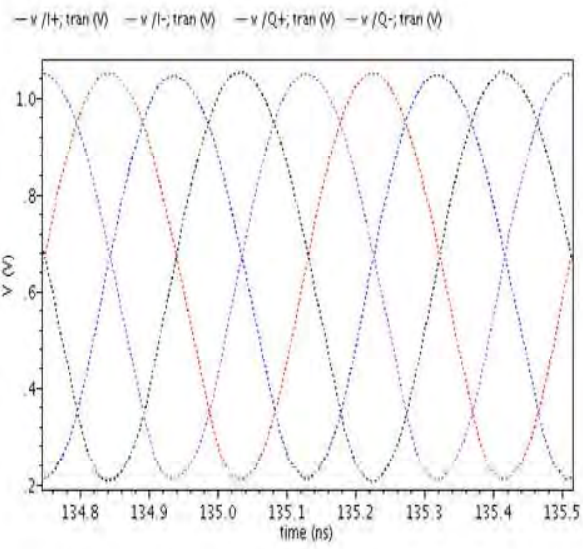

(a)
Periodic Noise Response

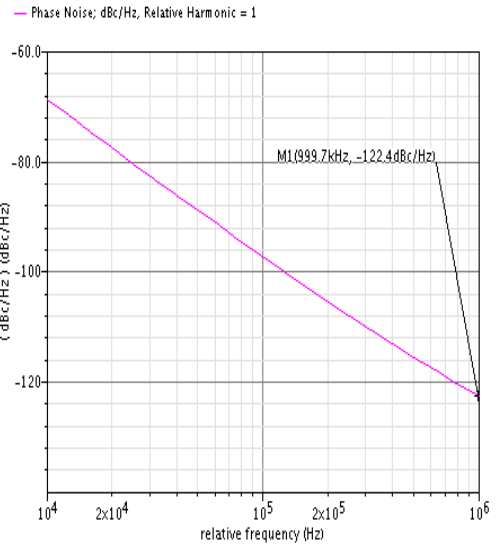

(b)

Fig. 17. a) Quadrature signals of S-QVCO b) Phase noise

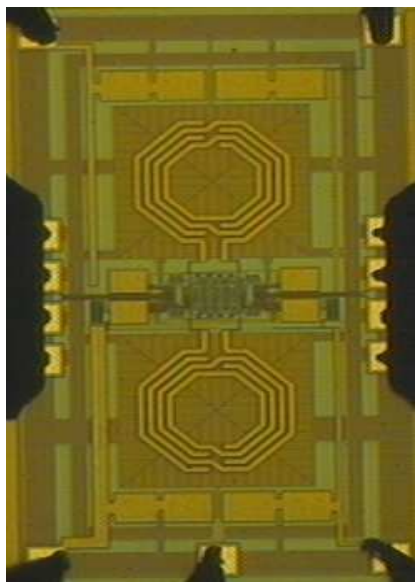

(a)

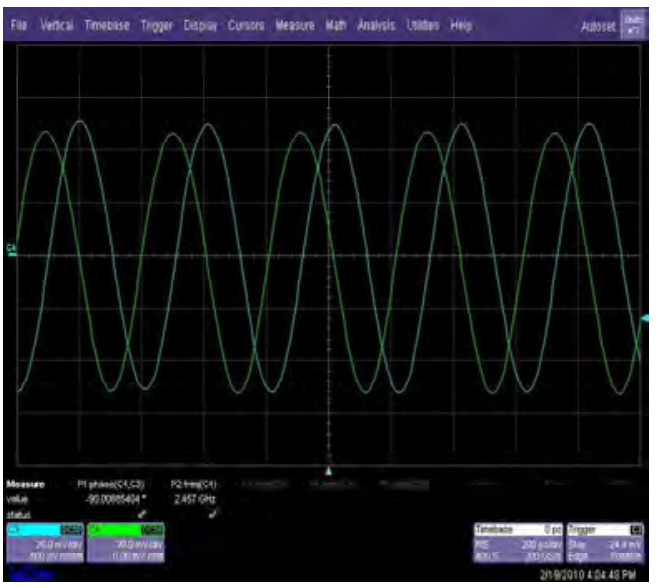

(b)

Fig. 18. a) die photograph of S-QVCO b) I/Q signal 
The current -reuse technique is used to further reduce the current consumption of the S-QVCO by adding cross-coupled PMOS transistors on top of the cross-coupled NMOS transistors. Open-drain transistors are added to the output nodes of the SQVCO to serve as the buffer to the testing equipment. The gain of the S-QVCO from post layout results is $280 \mathrm{MHz} / \mathrm{V}$ and Fig. 17 shows the quadrature output signals and phase noise of the S-QVCO. The S-QVCO has phase noise of $-122.4 \mathrm{dBc} / \mathrm{Hz}$ at 1 MHz. The 2/3 prescaler is directly driven by the S-QVCO and it requires input signal with smaller amplitude for low power consumption. Thus S-QVCO bias current can be reduced to provide smaller amplitude which in turn reduces the power consumption of S-QVCO.

The measured phase noise is $-122 \mathrm{dBc} / \mathrm{Hz}$ at $1 \mathrm{MHz}$ offset as shown in Fig.19 and the output signal amplitude is around $300 \mathrm{mV}$. The total power consumption of the SQVCO is $2.7 \mathrm{~mW}$ at $1.8 \mathrm{~V}$ power supply. A widely used figure of merit (FOM) for the VCO is defined as [14]

$$
F O M=L\left\{f_{\text {offset }}\right\}-20 \log \left(\frac{f_{o}}{f_{\text {offset }}}\right)+20 \log \left(\frac{P_{D C}}{1 m W}\right)
$$

Where $L\left\{f_{\text {offset }}\right\}$ is the measured phase-noise at offset frequency $f_{\text {offset }}$ from the carrier frequency $f_{\mathrm{o}}$. $\mathrm{P}_{\mathrm{DC}}$ is $\mathrm{VCO}$ power consumption in $\mathrm{mW}$. Table 3 summarizes the performance of the S-QVCO.

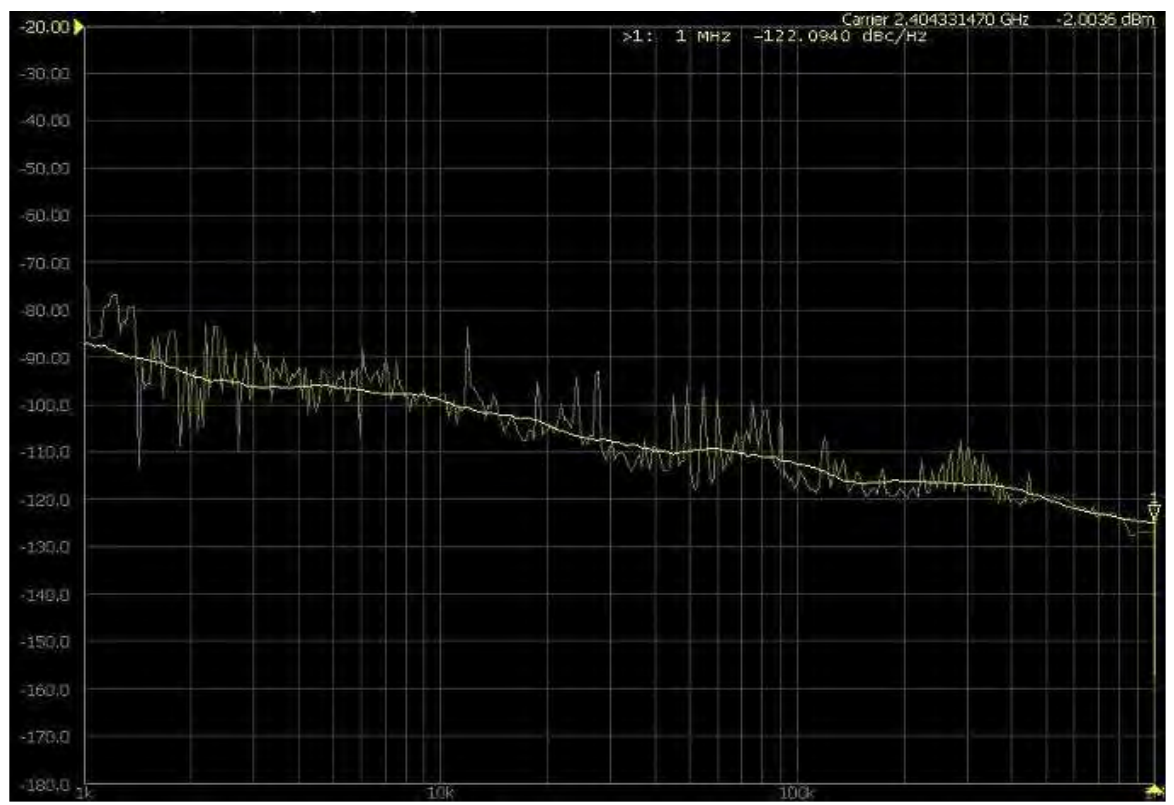

Fig. 19. Measured phase noise of the S-QVCO 
Table 3. Performance of S-QVCO

\begin{tabular}{|l|l|}
\hline Parameters & This Design \\
\hline Power supply & $1.8 \mathrm{~V}$ \\
\hline Technology & RF CMOS 0.18um \\
\hline Frequency & $2.2-2.7 \mathrm{GHz}$ \\
\hline Tuning range & $20.4 \%$ \\
\hline VCO gain (KVCO) & $414 \mathrm{MHz} / \mathrm{V}$ \\
\hline Phase Noise & $-122 \mathrm{dBc} / \mathrm{Hz} @ 1 \mathrm{MHz}$ offset \\
\hline Output amplitude & $300 \mathrm{mV}$ \\
\hline I/Q phase difference & $90.2^{\circ}$ \\
\hline Power consumption & $2.88 \mathrm{~mW}$ \\
\hline FOM & --177.4 \\
\hline
\end{tabular}

\section{Phase Frequency Detector (PFD) and Charge Pump (CP)}

The PFD used in this design is a conventional NAND based circuit [15] as shown in Fig.20 which consists of two TSPC DFF registers, a AND gate. A certain amount of delay is introduced after the AND gate before resetting the DFF to keep the pulse width of UP and DN signals finite so as to eliminate the problem caused by dead zone. The half-transparent DFF reported in [12] is implemented as the DFF register in this design. The dead-zone removal pulse is of $11 \mathrm{~ns}$, which is sufficient to turn-on UP and DN switches of the charge pump during the locked condition.

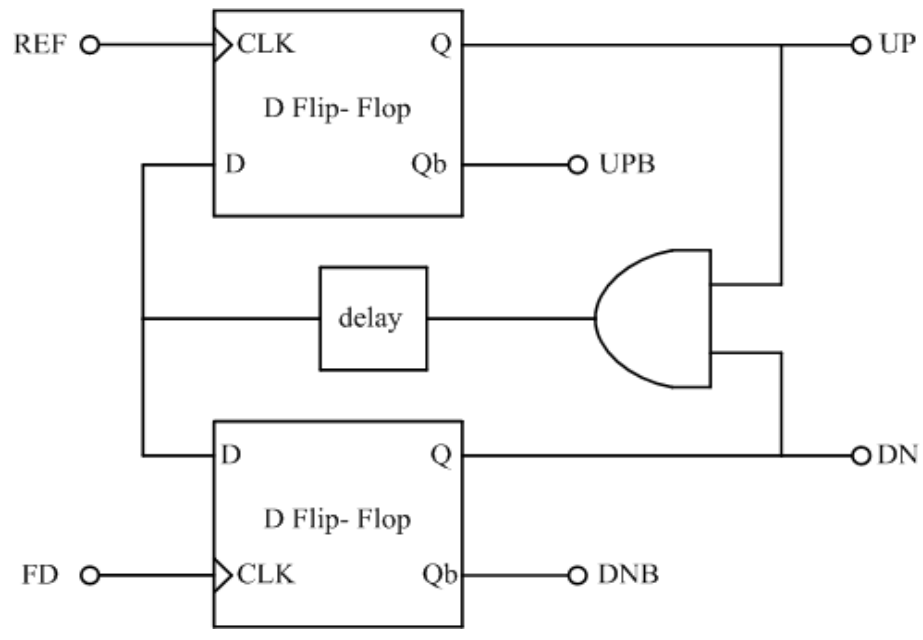

Fig. 20. Phase frequency detector (PFD)

The schematic of the charge pump used in the design of PLL synthesizer is shown in Fig.21. The charge pump circuit consists of two input differential pairs $\mathbf{M}_{1}-\mathbf{M}_{2}$ and $\mathrm{M}_{3}-\mathrm{M}_{4}$ which act as the switches, two current sources $\mathrm{M}_{5}$ and $\mathrm{M}_{6}$ supply stable current to the differential switches, a pump-up sub circuit formed by $M_{7}$ and $M_{12}$ 
outputs the charge current $I_{\text {charge }}$ and a pump-down sub-circuit formed by $\mathrm{M}_{8}, \mathrm{M}_{9}, \mathrm{M}_{10}$ and $\mathrm{M}_{11}$ which helps to discharge the current $\mathrm{I}_{\text {discharge. }}$.

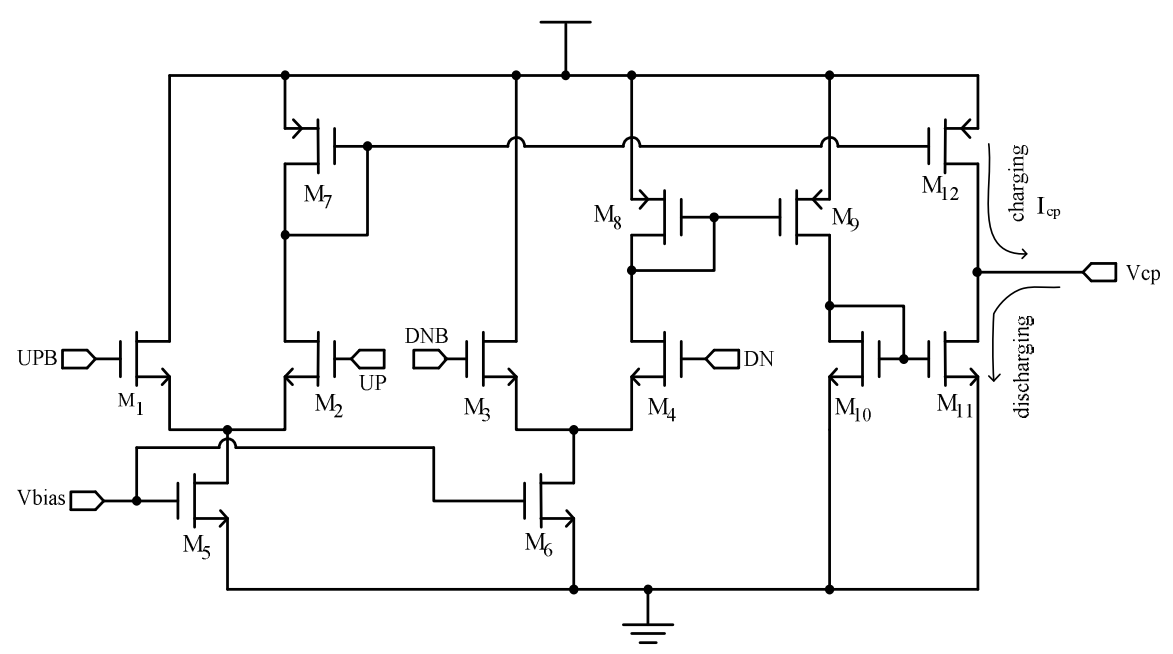

Fig. 21. Implemented Charge pump

Case-I: $U P=$ ' 1 ' and $D N=$ 'O'. When the UP signal is high (UP='1') and the DN signal is low (DN='0'), $\mathrm{M}_{4}$ is turned-off, $\mathrm{M}_{2}$ is turned-on which switches on the pump-up sub-circuit. Hence the charging current $\mathrm{I}_{\text {charge }}$ flows through $\mathrm{M}_{12}$ charging up the loop filter. Since $\mathrm{M}_{4}$ is turned-off, the pump-down sub-circuit is turned-off and no discharge current $\mathrm{I}_{\text {discharge }}$ current flows in $\mathrm{M}_{11}$.

DC Response

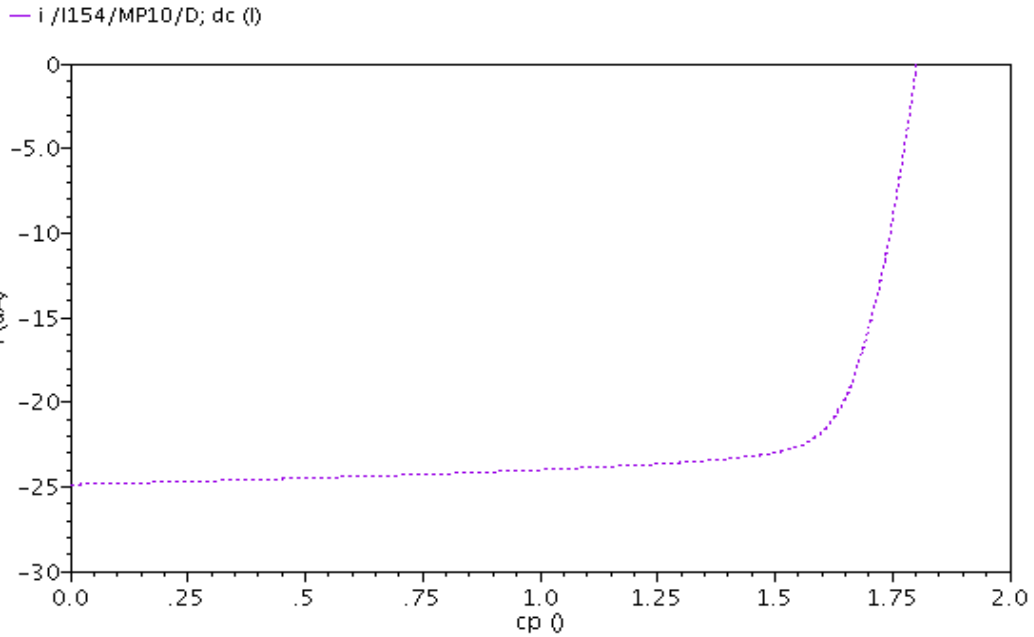

Fig. 22. Charging current from charge pump when UP is high and DN is low 
Case-II: UP=' $O^{\prime}$ and $D N={ }^{\prime} l$ '. When the UP signal is low (UP=' 0 ') and the DN signal is high ( $\left.\mathrm{DN}={ }^{\prime}{ }^{\prime}\right), \mathrm{M}_{2}$ is turned-off, $\mathrm{M}_{4}$ is turned-on which switches on the pump-down sub-circuit. Hence the discharging current $\mathrm{I}_{\text {discharge }}$ flows through $\mathrm{M}_{11}$ to the ground discharging the loop filter. Since $\mathrm{M}_{2}$ is turned-off, the pump-up sub-circuit is turned-off and no charge current $\mathrm{I}_{\text {charge }}$ current flows in $\mathrm{M}_{12}$. Fig.22 and Fig.23 shows the simulated DC simulations of UP and DN currents of the charge pump.

DC Response

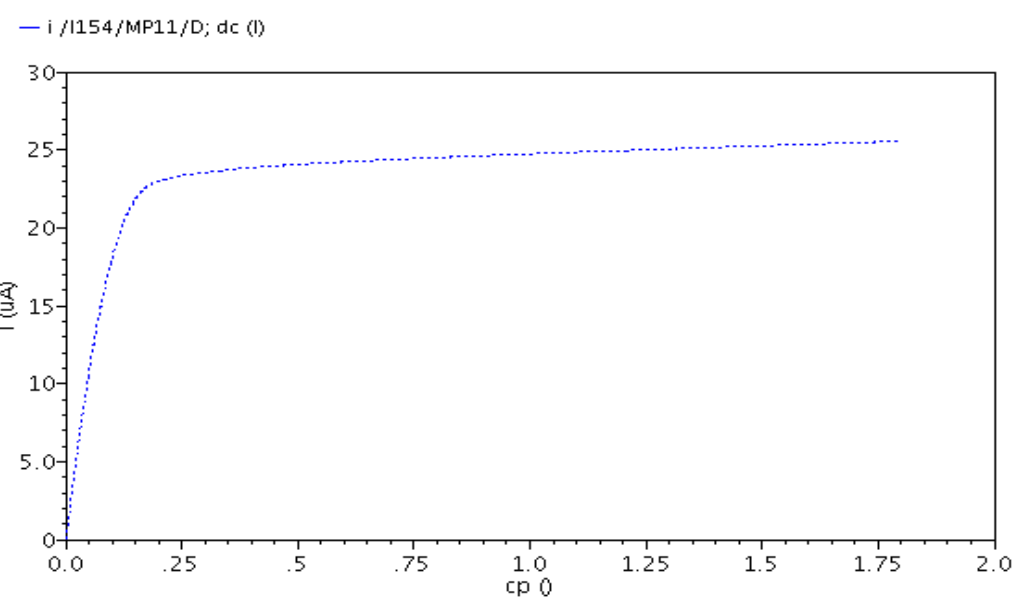

Fig. 23. Discharging current from charge pump when UP is low and DN is high

DC Response

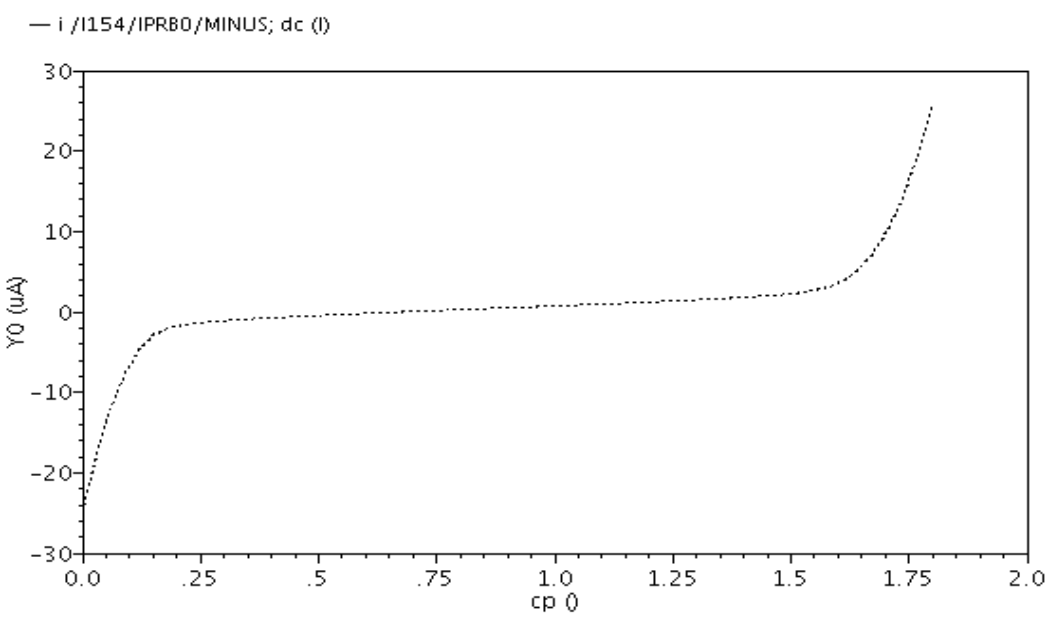

Fig. 24. Mismatch current from charge pump when UP and DN are high 
Case-III: $U P={ }^{\prime} l$ ' and $D N=' 1$ '. When both the UP and DN signals are driven high (UP='1' and $\mathrm{DN}={ }^{\prime} 1$ '), both $\mathrm{M}_{4}$ and $\mathrm{M}_{2}$ are turned-on and switch on both the pump-up and pump-down sub-circuits allowing the currents to steer through $\mathrm{M}_{11}$ and $\mathrm{M}_{12}$. If both charging $\left(\mathrm{I}_{\text {charge }}\right)$ and discharging $\left(\mathrm{I}_{\text {discharge }}\right)$ currents are equal, the charge stored on the loop filter remains same and doesn't affect the control voltage at the input of VCO. However, there exists a mismatch between charging and discharging current due to the mismatch of devices $\mathrm{M}_{11}$ and $\mathrm{M}_{12}$, and a net current of ( $\mathrm{I}_{\text {charge }}-\mathrm{I}_{\text {discharge }}$ ) leaks in to the loop filter and alters the control voltage.

In this design, both the differential switches $\mathrm{M}_{1}-\mathrm{M}_{2}$ and $\mathrm{M}_{3}-\mathrm{M}_{4}$ are implemented by NMOS transistors to avoid the switching mismatches. To have precise matching in the charging and discharging currents, the length of the output stage transistors are kept high to increase the output impedance. Here the charge pump current chosen is 25 uA. Fig. 24 shows the mismatch between the UP and down currents and the average mismatch current is around $1.4 \mathrm{uA}$.

\section{Loop filter Design}

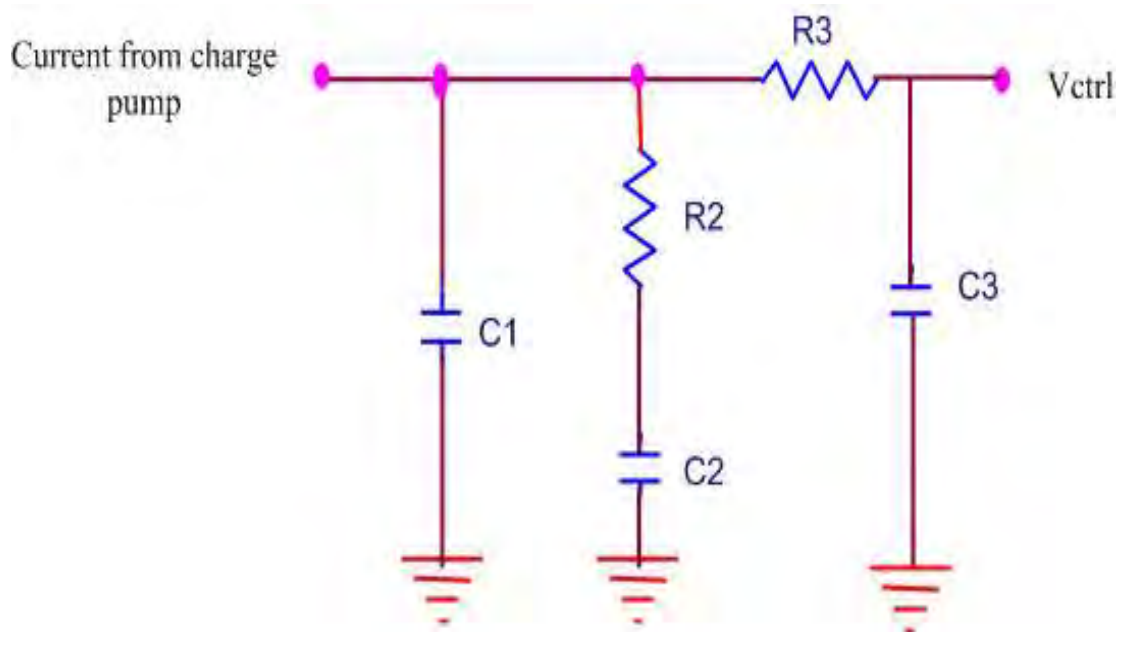

Fig. 25. $3^{\text {rd }}$ order loop filter

The loop filter used in this design is $3^{\text {rd }}$ order as shown in Fig. 25. The loop filter parameters are imposed by the system level performance specifications such as settling time, phase noise and spur suppression. Initially a $2^{\text {nd }}$ order filter is designed and later a RC low-pass section is added to improve the spurs and reduce the ripples on control voltage. The reference frequency used in this design is $1 \mathrm{MHz}$. The $2^{\text {nd }}$ order filter is assumed to be a critically damped system $(\xi=1)$ with a loop bandwidth $\left(f_{c}\right)$ of $45 \mathrm{KHz}$ to satisfy the Gardner's stability criterion [16]. For an optimal stability, for a passive second order filter, the relation between unity gain cross-over frequency $\left(\omega_{c}\right)$ and natural frequency $\left(\omega_{n}\right)$ is given by [17] 
$\omega_{c}=2 \xi \omega_{n}$

Since the damping factor is equal to unity, the natural frequency $\left(f_{n}\right)$ is found to be $22.5 \mathrm{KHz}$. For a charge pump PLL with $2^{\text {nd }}$ order loop filter and damping factor $\xi=1$, the relation between zero frequency $\left(f_{z 1}\right)$ and cross-over frequency $\left(f_{c}\right)$ is given by [5]

$4=\frac{\left(K_{v c o} I_{c p} R_{2}\right) \times\left(C_{2} R_{2}\right)}{2 \pi N}=\frac{f_{c}}{f_{\mathrm{Z} 1}}$

Similarly, the relation between pole frequency $\left(f_{p 1}\right)$ and cross-over frequency $\left(f_{c}\right)$ is given by

$4=\frac{\left(K_{v c o} I_{c p} R_{2}\right) \times\left(C_{2} R_{2}\right)}{2 \pi N}=2 \pi f_{c}\left(16 \times C_{1} R_{2}\right)=\frac{16 \times f_{c}}{f_{P 1}} \Rightarrow f_{P 1}=4 f_{c}$

Based on (9) and (10), the zero frequency and pole frequency are $11.25 \mathrm{KHz}$ and 180 $\mathrm{KHz}$ respectively. The phase margin is given as

$\phi=\tan ^{-1}\left(\frac{f_{c}}{f_{z 1}}\right)-\tan ^{-1}\left(\frac{f_{p 1}}{f_{c}}\right)=\tan ^{-1}(4)-\tan ^{-1}\left(\frac{1}{4}\right)=61.92^{\circ}$

With a charge pump current of $25 \mathrm{uA}\left(I_{c p}\right)$, VCO gain $\left(K_{v c o}\right)$ of $414 \mathrm{MHz} / \mathrm{V}$ and division ratio $(N)$ of 2450 , the values of $R_{2}, C_{2}$ and $C_{1}$ are calculated as,

$C_{2}=\frac{I_{c p} \times K_{v c o}}{2 \pi \times N \times\left(2 \pi f_{n}\right)^{2}}=207 p F$

$R_{2}=\frac{1}{2 \pi \times f_{z 1} \times C_{2}}=78.5 \mathrm{k} \Omega$

$C_{1}=\frac{C_{2}}{16}=12.9 p F$ 
The open loop PLL with a $2^{\text {nd }}$ order loop filter is simulated in Matlab and Fig.26 shows the root locus plot of the open loop PLL. Fig.27 shows the simulated Bode diagram of the open loop PLL where the phase margin is around 62. Fig. 28 shows the open loop gain and phase margin.

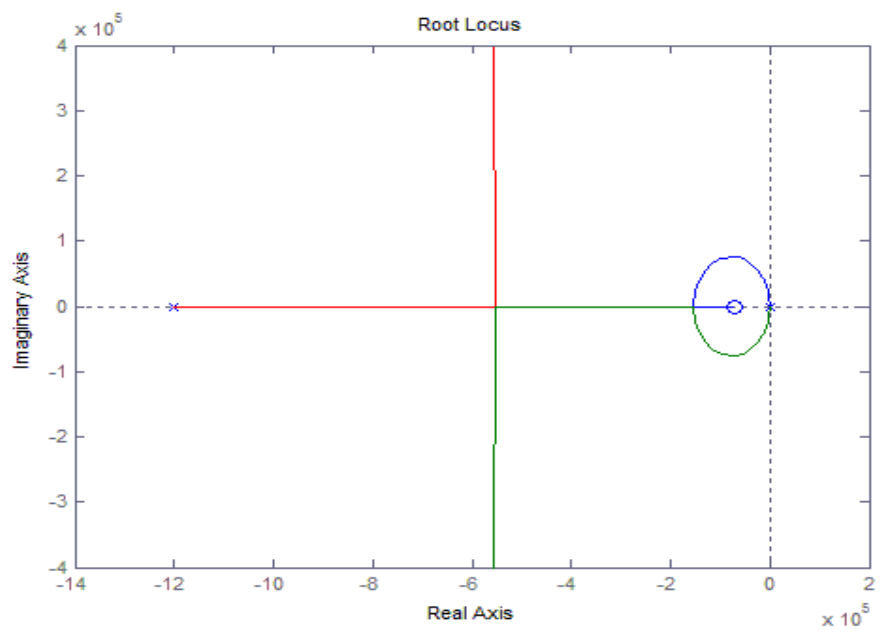

Fig. 26. Root locus of open loop PLL with $2^{\text {nd }}$ order filter

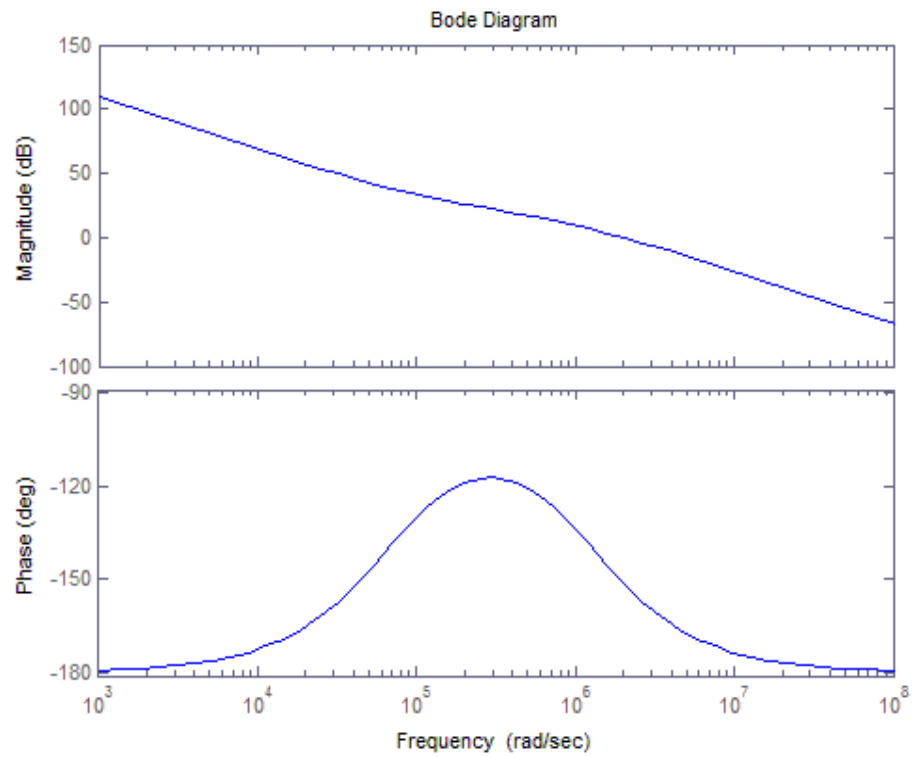

Fig. 27. Bode plot with $2^{\text {nd }}$ order filter 

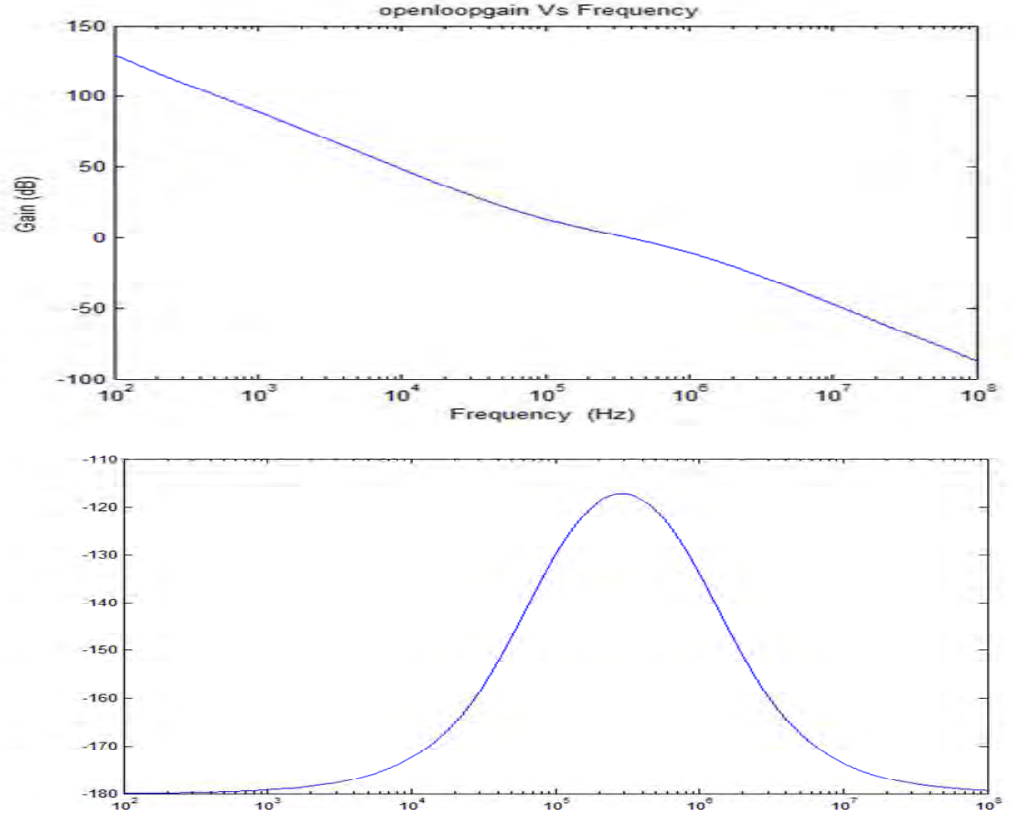

Fig. 28. Open loop response of PLL

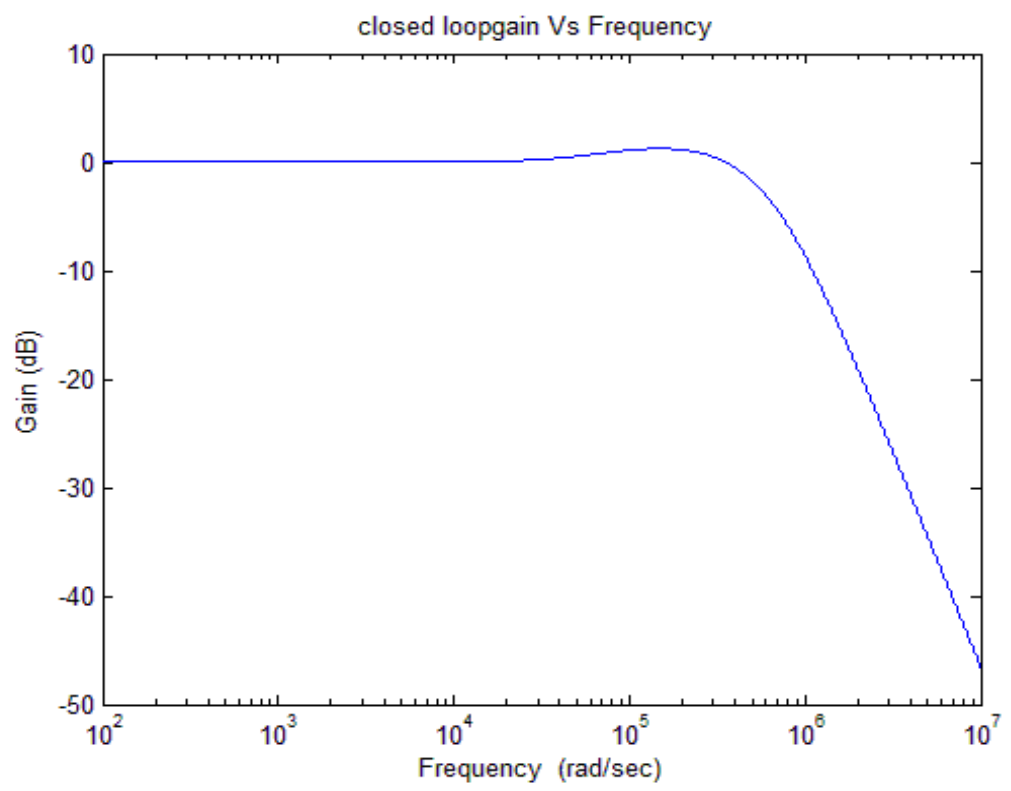

Fig. 29. Closed loop gain of PLL 


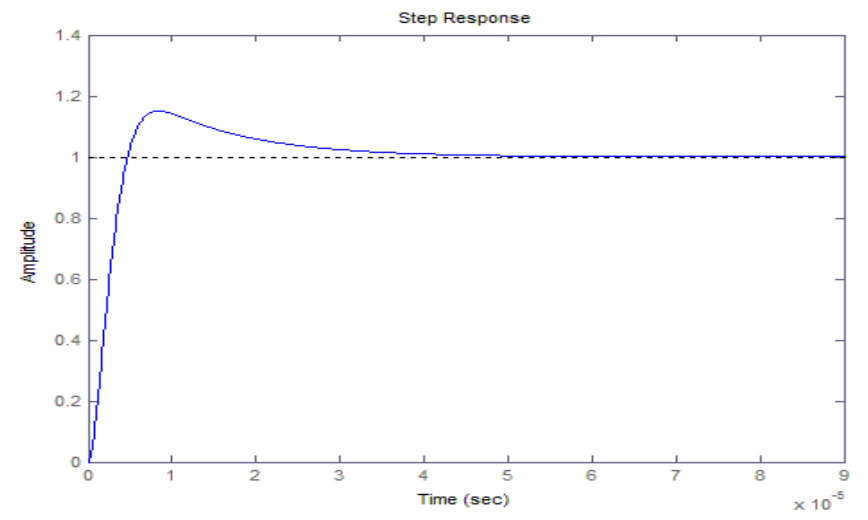

Fig. 30. Step response of the closed loop PLL

Fig. 29 and Fig. 30 shows the closed loop gain and step response of the PLL. An additional RC low pass section is added to reduce the amount of reference spurs at the cost of reduced phase margin and increased settling time. The additional RC low pass section is added to the $2^{\text {nd }}$ order filter such that the phase margin won't reduce to lesser value than 55 degrees. With additional RC section, damping factor reduces to slightly less than 1 . The value of $R_{3}$ and $C_{3}$ are found to be $98.9 \mathrm{Kohms}$ and $3.75 \mathrm{pF}$ respectively. With frequency accuracy of $40 \mathrm{ppm}$, the calculated settling time is $48 \mu \mathrm{s}$, which is nearly four times less than the required settling time for IEEE 802.15.4 standard (192 $\mu \mathrm{s})$.

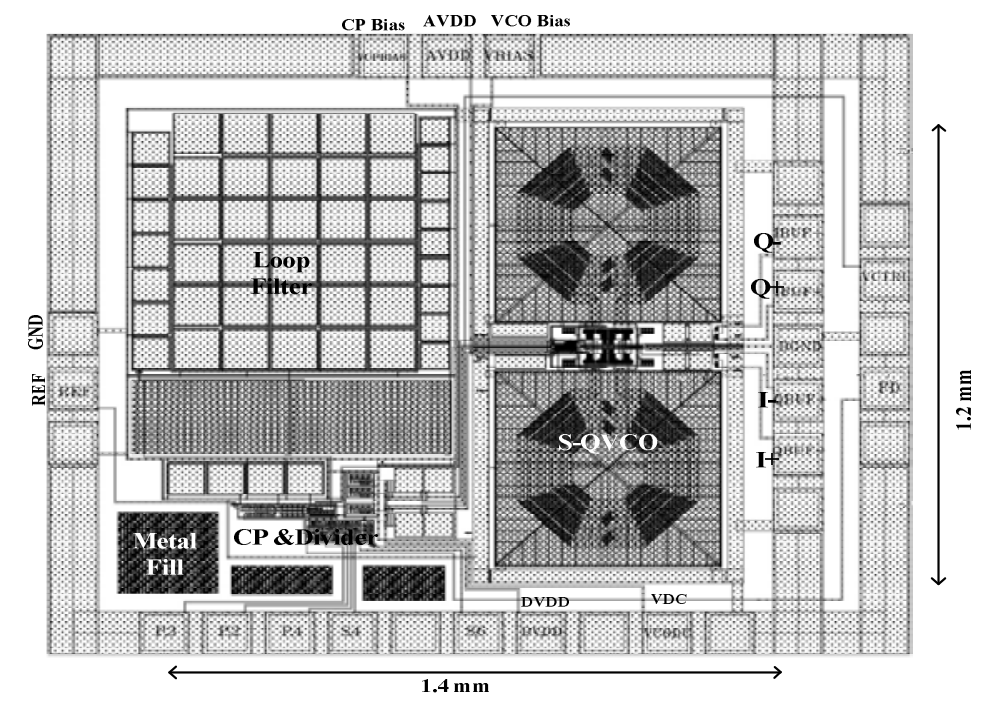

Fig. 31. Layout of $2.4 \mathrm{GHz}$ frequency synthesizer with testing pads 
The layout of the fully programmable $2.4 \mathrm{GHz}$ synthesizer with on-chip $3^{\text {rd }}$ order loop filter and testing pads is shown in Fig. 31. The synthesizer occupies an area of $1.4 * 1.2 \mathrm{~mm}^{2}$ with testing pads and the core area is $0.95 * 0.9 \mathrm{~mm}^{2}$. The simulations are performed using Cadence SPECTRE RF for a 0.18um CMOS process. The settling time for the synthesizer is around $58 \mu \mathrm{s}$ which is 4 times lesser than the value required by IEEE 802.15 .4 standard.

Transient Response

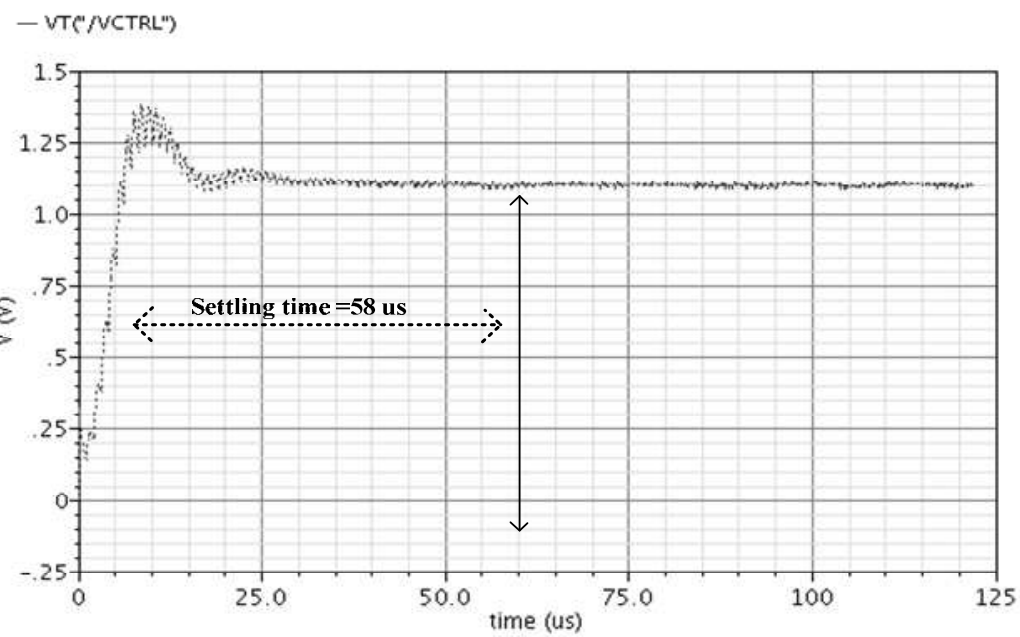

Fig. 32. Settling behavior of the implemented frequency synthesizer

Transient Response

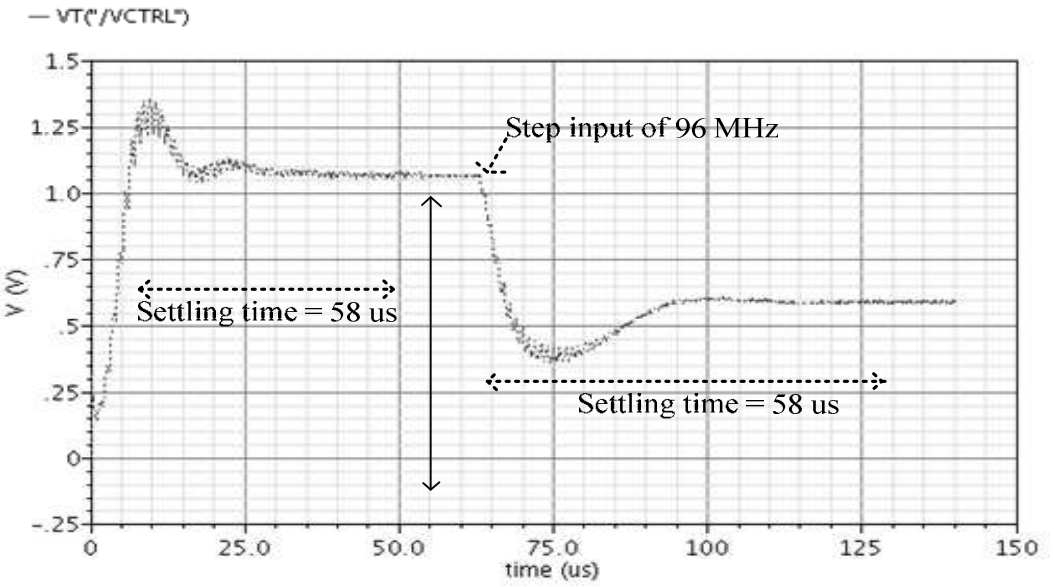

Fig. 33. Settling behavior of synthesizer with change of N from 2400 to 2496 
Fig.32 shows the settling behavior of the synthesizer for fixed channel which shows the settling time is around 58 us. Fig.33 shows the settling behavior of the synthesizer when the division ratio is changed from 2400 to 2496 . The implemented fully programmable $1 \mathrm{MHz}$ resolution frequency synthesizer consumes $3.6 \mathrm{~mW}$ (2 $\mathrm{mA}$ ) from a power supply of $1.8 \mathrm{~V}$, which is significantly lesser than the synthesizers reported in literature implemented with dynamic logic dividers.

\section{Measured Results}

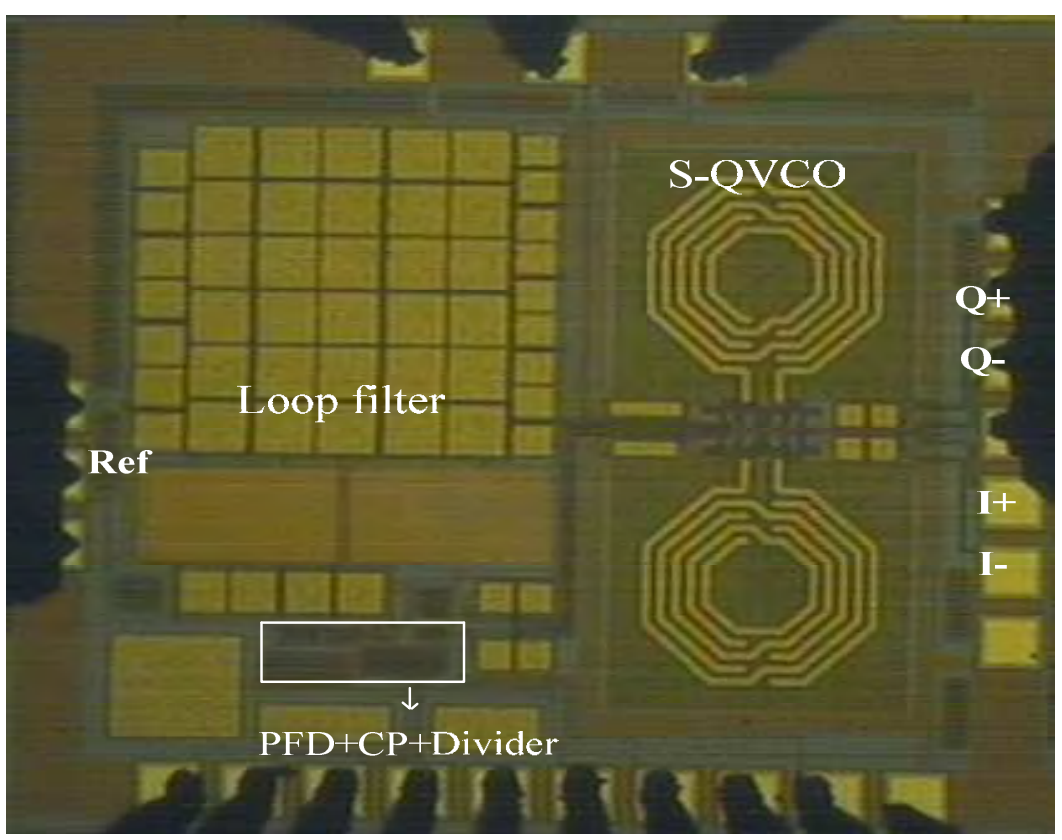

Fig. 34. Die photograph of $2.4 \mathrm{GHz}$ PLL frequency synthesizer

For silicon verification, the proposed fully programmable $2.4 \mathrm{GHz}$ frequency synthesizer is fabricated using the chartered 1P6M 0.18 um CMOS process. Fig.34 shows the die photograph of the implemented $2.4 \mathrm{GHz}$ frequency synthesizer. Onwafer measurements are carried out using an 8 inch RF probe station. The input signal for the measurement is provided by the Agilent 33120A arbitrary signal generator and the output signals are captured by the Lecroy Wave master 8600A 6G oscilloscope. The output spectrum and phase noise of the synthesizer is measured using the Agilent E4407B $9 \mathrm{kHz}-26.5 \mathrm{GHz}$ spectrum analyzer. Fig.35 shows the measured output spectrum of the PLL. 


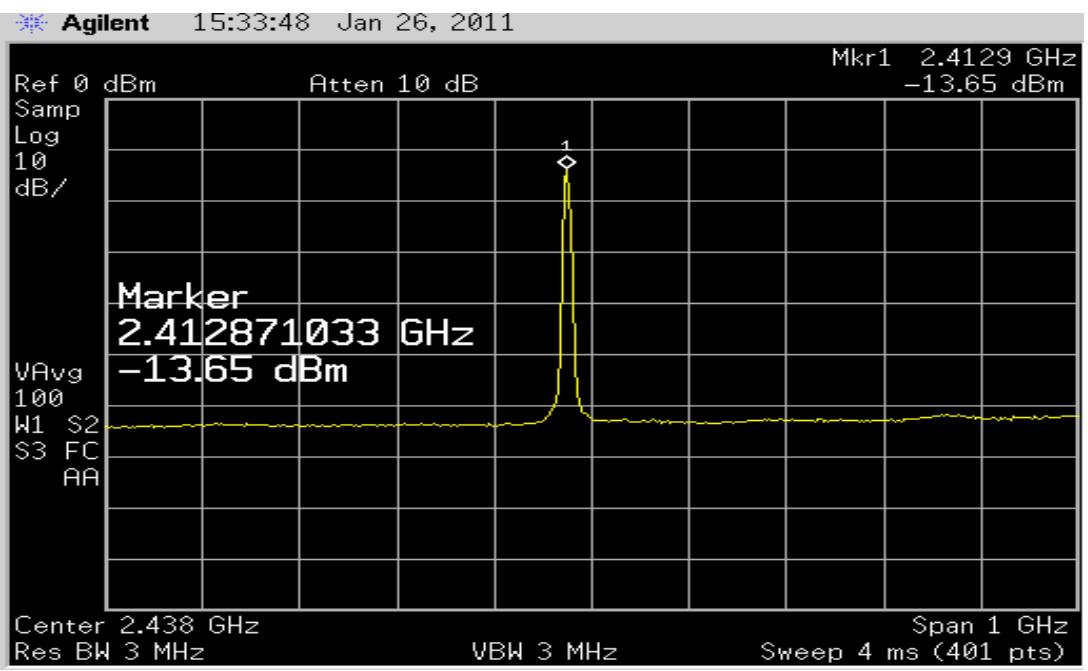

Fig. 35. Measured PLL output spectrum

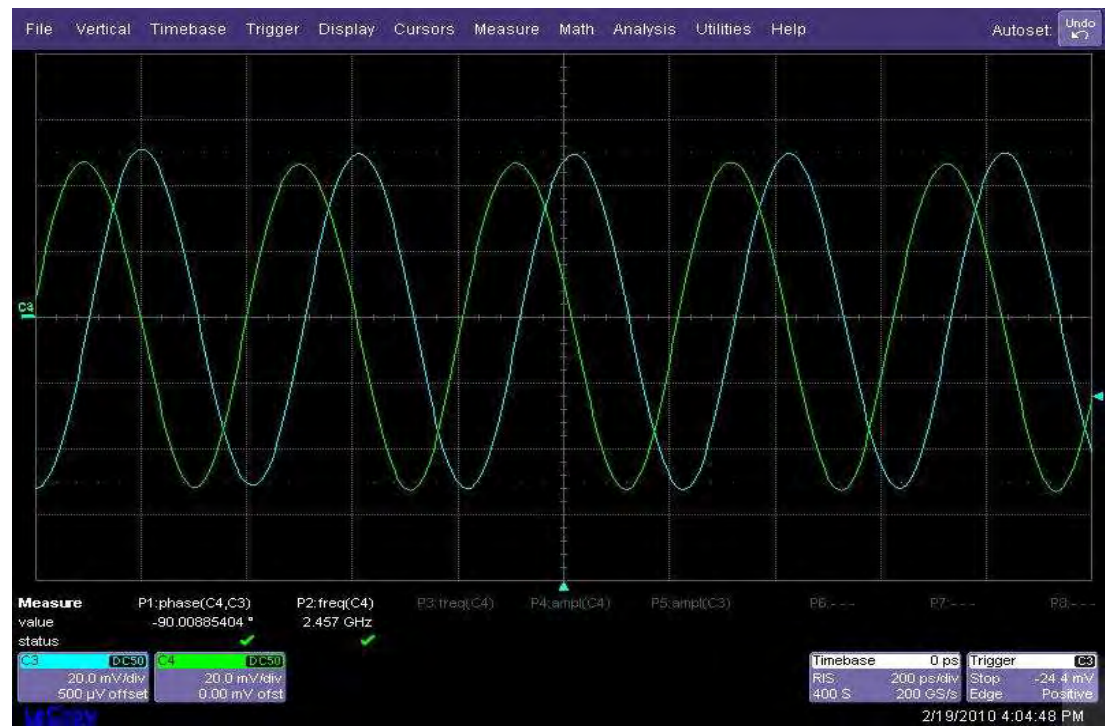

Fig. 36. Measured I/Q signal at PLL output

The VCO tuning range is from $2.369 \mathrm{GHz}-2.692 \mathrm{GHz}(323 \mathrm{MHz})$ and output amplitude is around $300 \mathrm{mV}$ as shown in Fig.36. The power consumption of S-QVCO is $2.9 \mathrm{~mW}$. The measured ripples on the control voltage is around $1 \mathrm{mV}$ and power consumption of divider, charge pump other blocks is around $0.9 \mathrm{~mW}$. Fig. 37 shows the $1 \mathrm{MHz}$ output from the fully programmable divider whose duty cycle is around $43 \%$. The phase noise of the PLL is $-111.4 \mathrm{dBc} / \mathrm{Hz}$ at $1 \mathrm{MHz}$ offset as shown in 
Fig.38. The performance of the implemented low power $2.4 \mathrm{GHz}$ frequency synthesizer is analyzed in Table 4.

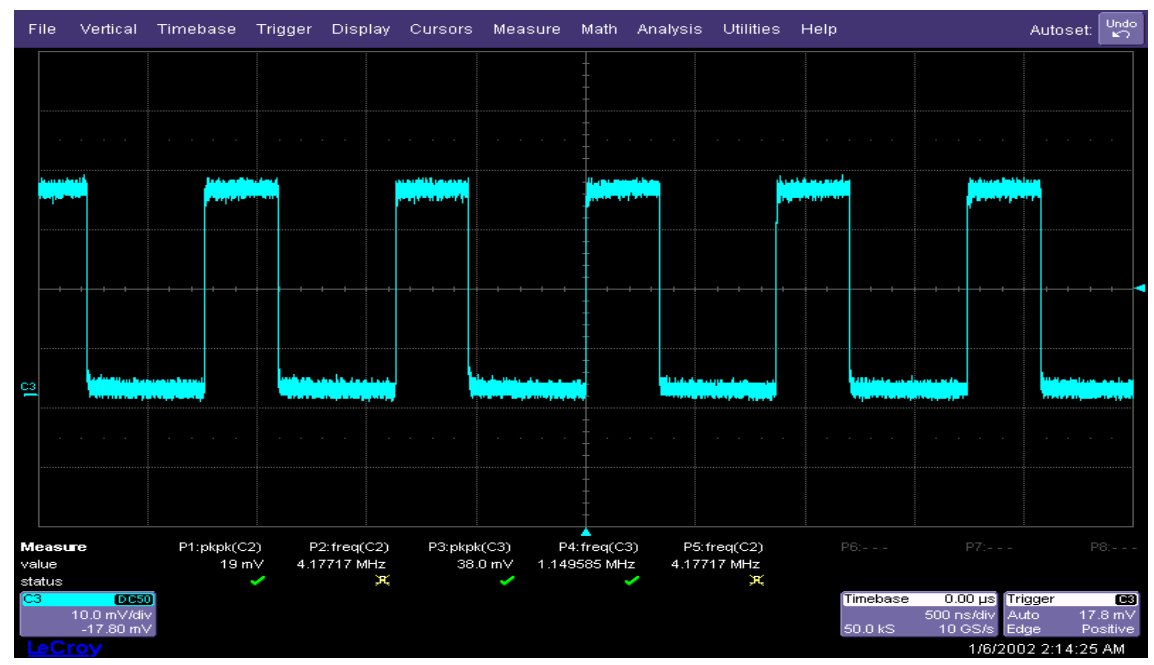

Fig. 37. Measured $1 \mathrm{MHz}$ output of the divider

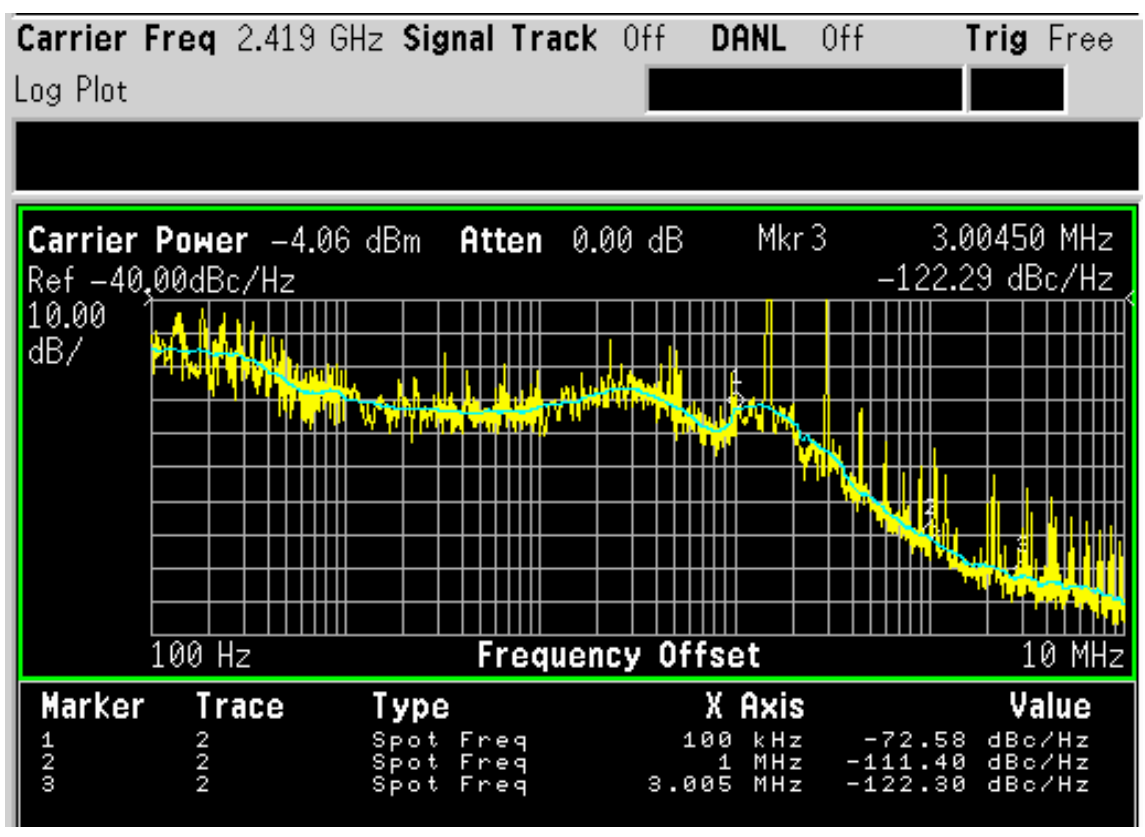

Fig. 38. Measured PLL output phase noise 
Table 4. State of Art Synthesizer Comparison

\begin{tabular}{|c|c|c|c|c|c|}
\hline Reference & [4] & [5] & [18] & [19] & $\begin{array}{l}\text { This } \\
\text { work }\end{array}$ \\
\hline Process & $0.25 \mathrm{um}$ & $0.18 \mathrm{um}$ & $0.18 \mathrm{um}$ & $\begin{array}{c}0.2 \mathrm{um} \\
\mathrm{CMOS} / \mathrm{SOI}\end{array}$ & $0.18 \mathrm{um}$ \\
\hline $\begin{array}{l}\text { Channel } \\
\text { spacing }\end{array}$ & $1 \mathrm{MHz}$ & $5 \mathrm{MHz}$ & $3 \mathrm{MHz}$ & $1 \mathrm{MHz}$ & $1 \mathrm{MHz}$ \\
\hline $\begin{array}{l}\text { Frequency } \\
\text { Range }(\mathrm{GHz})\end{array}$ & $2.4-2.527$ & $2.29-2.64$ & $2.44-2.47$ & 2.4 & $2.2-2.5$ \\
\hline Loop filter & On- chip & On- chip & On- chip & Off- chip & On- chip \\
\hline $\begin{array}{l}\text { Phase noise } \\
(\mathrm{dBc} / \mathrm{Hz})\end{array}$ & $\begin{array}{l}-112 \\
@ 1 \mathrm{MHz}\end{array}$ & $\begin{array}{l}-130 \\
@ 10 \mathrm{MHz}\end{array}$ & $\begin{array}{l}-112 \\
@ 1 \mathrm{MHz}\end{array}$ & $\begin{array}{l}-104 \\
@ 1 \mathrm{MHz}\end{array}$ & $\begin{array}{l}-111.4 \\
@ 1 \mathrm{MHz}\end{array}$ \\
\hline Settling time & 60 us & 55 us & 500 us & 600 us & 35 us \\
\hline $\begin{array}{l}\text { Power } \\
\text { consumption }\end{array}$ & $\begin{array}{l}20 \mathrm{~mW} \\
\text { at } 2.5 \mathrm{~V}\end{array}$ & $\begin{array}{l}15 \mathrm{~mW} \text { at } \\
3 \mathrm{~V}\end{array}$ & $\begin{array}{l}8.2 \mathrm{~mW} \\
\text { at } 1.8 \mathrm{~V}\end{array}$ & $\begin{array}{l}17 \mathrm{~mW} \\
\text { at } 1 \mathrm{~V}\end{array}$ & $\begin{array}{l}4.9 \mathrm{~mW} \\
\text { at } 1.8 \mathrm{~V}\end{array}$ \\
\hline
\end{tabular}

\section{Conclusion}

In this paper, a fully integrated $1 \mathrm{MHz}$ resolution $2.4 \mathrm{GHz} \mathrm{CMOS}$ frequency synthesizer for IEEE 802.15.4 standard is designed using Global foundries $0.18 \mathrm{um}$ CMOS technology is presented. A new 47/48 dual-modulus prescaler based on truesingle phase clock is proposed along with the improved reloadable DFF for the swallow S-counter. The fully programmable divider only consumes $600 \mathrm{uW}$ which is very compared to the fully programmable dividers reported in literature. The measured tuning range of the S-QVCO is $2.369 \mathrm{GHz}-2.692 \mathrm{GHz}$ and the output amplitude is $300 \mathrm{mV}$, which is sufficient to drive the divider. The phase noise of the PLL is $-111.4 \mathrm{dBc} / \mathrm{Hz}$ at $1 \mathrm{MHz}$ offset and the total power consumption of the synthesizer is $3.8 \mathrm{~mW}$.

\section{Acknowledgments}

The authors would also like to acknowledge the help of W. M. Lim, and T. S. Wong, Nanyang Technological University, Singapore, in the on-wafer measurement. 


\section{References}

1. Aaron V. Do, C.C. Boon, M.A. Do, K.S. Yeo and A. Cabuk, "An Energy-Aware CMOS Receiver Front End for Low-Power 2.4-GHz Applications", IEEE Tran. On Circuits and Systems-I: Regular papers (TCAS-I), vol. 51, no.9, pp. 1665-1674, April.2010.

2. Debashis.M and T.K.Bhatacharyya, "Implementation of CMOS Low-Power Integer-N Frequency Synthesizer for SOC Design", Journal of Computers, vol. 3, no. 4, pp. 31-38, April 2008.

3. C.Bernier, et.al, "An ultra-low power 130nm CMOS direct conversion transceiver for IEEE 802.15.4”, IEEE Radio Frequency Circuits Symposium, pp. 273-276, June 2008.

4. T.C.Lee and B.Razavi, "A stabilization Technique for Phase-Locked Frequency Synthesizers", IEEE Journal of Solid-State Circuits, vol. 38, pp. 888-894, June 2003.

5. Rangakrishnan Srinivasan, et.al, "A Low-Power Frequency Synthesizer with Quadrature Signal Generation for 2.4 GHz Zigbee Applications”, IEEE ISCAS, pp. 429-432, 2007.

6. Roberto Nonis et.al, "A Design Methodology for MOS Current-Mode Logic Frequency Dividers”, IEEE Trans. Circuits \& Systems-I: Reg. Papers, vol. 54, no.2, pp. 245-254, Feb. 2007.

7. N -J. Oh, S-G. Lee, A CMOS 868/915 MHz Direct Conversion Zigbee Single-Chip Radio", IEEE Communications Magazine, vol. 43, issue 12, pp. 100-109, Dec, 2005.

8. P. Gorday, "802.15.4 Multipath”, July, 2005.

9. Y. Ji-ren, I. Karlsson, and C. Svensson, "A true single-phase clock dynamic CMOS circuit technique”, IEEE J. Solid-State Circuits, Vol. 24, no. 2, pp. 62-70, Feb. 1989.

10.M.Vamshi Krishna, et.al, "Design and Analysis of Ultra Low Power True Single Phase Clock CMOS 2/3 Prescaler", IEEE Trans. Circuits \& Systems-I: Reg. Papers, vol. 57, no.1, pp. 72-82, Jan. 2010.

11.X.P.Yu, M.A.Do, L.Jia, J.G.Ma and K.S.Yeo, "Design of a low power wide-band high resolution programmable frequency divider," IEEE Trans. on Very Large Scale Integration Systems, vol. 13, no.9, Sep.2005.

12.W.S.T. Yan, A 2-V 900-MHz Monolithic CMOS Dual-Loop Frequency Synthesizer for GSM Receivers, Master Thesis, Department of EEE, HKUST, Nov. 1999.

13.P. Andreani, "A low phase noise low phase error $1.8 \mathrm{GHz}$ quadrature CMOS VCO", Proc. of IEEE ISSCC, pp. 290-291, Feb. 2006.

14.N. Fong, J. Plouchart, N. Zamdmer, D. Liu, L. Wagner, C.Plett, and N. Tarr, "Design of wide-band CMOS VCO for multiband wireless LAN applications", IEEE J. Solid-State Circuits (JSSC), vol. 38, no.8, pp. 1333-1342, Aug. 2003.

15.B.Razavi, "Monolithic Phase-Locked Loops and Clock Recover Circuits", NJ: IEEE Press, 1996.

16. F. Gardner, "Charge Pump Phase-Lock Loops", IEEE Trans. On communications, vol. 28, pp. 1849-1858, Nov. 1980.

17. Dean Banerjee, PLL Performance, Simulation, and Design, $4^{\text {th }}$ edition, 2006

18.A.Yamagishi, M.Ugajin and T.Tsukahara, "A 1-V 2.4-GHz PLL Synthesizer with a fully differential prescaler and a Low-off-Leakage charge pump", in Microwave Symposium Digest, pp. 733-736, June 2003.

19.Sangho Shin, Kwyro Lee and Sung-Mo Kang, "Low Power 2.4GHz CMOS Frequency Synthesizer with Differentially Controlled MOS Varactors", IEEE ISCAS, pp. 553-556, May 2006. 